\title{
Estratégias de cooperação tecnológica transnacional em Estados Unidos e Japão: uma comparação a partir de dados de patentes
}

\author{
Ana Urraca Ruiz \\ Universidade Federal Fluminense (UFF), Niterói (RJ), Brasil \\ Cynthia Bastos Gomes \\ Universidade Federal Fluminense (UFF), Niterói (RJ), Brasil
}

Recebido: 21/12/2011 Versão Revisada (entregue): 27/03/2012 Aprovado: 17/05/2012

\begin{abstract}
Resumo
Este trabalho tem como objetivo definir uma metodologia para identificar as principais estratégias de cooperação tecnológica transacional e aplicá-la aos casos de Estados Unidos e Japão. Este exercício permitirá comprovar as hipóteses relativas ao novo modelo de rede que caracteriza a internacionalização da atividade inovadora na busca pelas competências tecnológicas que se estendem pelo mundo, mas que se concentram na tríade Estados Unidos-Europa-Japão. A partir de patentes depositadas em conjunto na European Patent Office, entre 1985 e 2008, o trabalho confirma a existência de estratégias pela busca de competências dentro da tríade, com o objetivo de explorar complementaridades e vantagens domésticas.
\end{abstract}

PalaVras-Chave | Cooperação Tecnológica; Internacionalização; Estados Unidos; Japão.

Códigos JEL | O32; O39.

As autoras agradecem os comentários e sugestões de dois avaliadores anônimos da Revista Brasileira de Inovação. Falhas ou omissões são de responsabilidade única das autoras. 
Ana Urraca Ruiz, Cynthia Bastos Gomes

\title{
Transnational technological cooperation strategies in United States and Japan: a comparison from patent data
}

\begin{abstract}
This paper aims to define a methodology to identify the main strategies of technological cooperation and to apply it to the United States and Japan. This exercise allows to test the hypothesis respecting to the new organization model of innovative activity internationalization (network model). Under this model, transnational corporations are motivated by looking for technological competences widespread across the whole world, but highly concentrated in triad United States-Japan-Europe. Using join deposits of patents in European Patent Office between 1985 and 2008, the paper confirms the existence of this kind of strategies exploring complementarities with the partners or by exploiting domestic advantages.
\end{abstract}

KEYwORDS | Technological Cooperation; Internationalization; United States; Japan.

JEL-CODES | O32; O39.

\section{Introdução}

O fenômeno da cooperação tecnológica transnacional é relativamente recente. Sua observação começou a se tornar mais visível a partir da década de 1980 (HAGEDOORN; SOETE, 1991; ARCHIBUGI; MICHIE, 1995), normalmente concentrado num pequeno número de setores intensivos em P\&D (biotecnologia, novos materiais e tecnologia de informação) e em países da tríade Estados Unidos-Japão-Europa.

A cooperação tecnológica transacional surge da evolução da estrutura organizativa das Grandes Corporações Transnacionais (GCT) que, desde seu início nos anos 1960, registrou fortes mudanças. A partir de meados da década de 1990 e durante a de 2010, a trajetória de descentralização foi se acentuando de tal forma que a literatura começou a falar de um novo Modelo Rede. A ideia de rede atende 
a uma dimensão interna que consiste em "the interconnection of a large number of internal units that are deeply involved in the company's use and generation of knowledge." e a uma dimensão externa, ou seja, "other firms and institutions that are located outside the boundaries of the TNC, in order to increase the potential for use and generation of knowledge" (ZANFEI, 2000, p. 516). Tais conexões costumam ser realizadas mediante parcerias, acordos de cooperação em $\mathrm{P} \& \mathrm{D}$, alianças tecnológicas ou contratos de pesquisa com fornecedores, usuários locais ou universidades locais. O estabelecimento de ambos os tipos de conexóes pode ser observado tanto nas matrizes quanto nas subsidiárias e tem empurrado as GCT a uma crescente dispersão de seus ativos estratégicos, como são P\&D e outras atividades baseadas em conhecimento.

O novo modelo decorre de uma nova concepção da internacionalização baseada nos ganhos da descentralização em oposição à justificativa dos ganhos da aglomeração dos modelos centralizados durante os anos 1970. Esta concepção entende as subsidiárias como agentes capturadores de competências tecnológicas e de ideias relevantes, participando ativamente no processo de acumulação tecnológica da corporação. O novo papel das subsidiárias não é mais do que a resposta das corporações à "heterogeneidade da economia global" em termos de heterogeneidade tecnológicaou as diversas potencialidades que oferecem os países de acordo com seus Sistemas Nacionais de Inovação - e em termos de heterogeneidade de mercado - ou diversidade de aspectos que adquirem os mercados em cada país (FILIPPAIOS et al., 2009). O processo de internacionalização passa a ser qualificado como de "individualismo interdependente", em que a individualidade das subsidiárias se expressa na aquisição de capacidades tecnológicas específicas que contribuem para a competitividade do grupo (corporação), mas em cujo processo é preciso que exista a interdependência com as outras unidades (PAPANASTASSIOU; PEARCE, 1995). O conhecimento adquire funções de caráter organizacional para permitir a evolução do grupo, dado que ele opera em contextos específicos, mas faz parte de um "todo" mais amplo (FILIPPAIOS et al., 2009).

Neste cenário, as corporaçôes desenvolvem o que Filippaios et al. (2009) denominam de "novas estratégias de internacionalização", com os seguintes objetivos:

- dado que as fontes das vantagens tecnológicas não estão localizadas num único país, as novas estratégias devem habilitar as empresas a explorar novas oportunidades, desenvolver habilidades focadas no exterior e criar "novos negócios" ou "novos conceitos de produtos" em qualquer lugar do mundo, para o qual surge uma estrutura organizativa fundamental: 
as redes (ZANFEI, 2000; GHOSHAL; BARTLETT, 1995; FILIPPAIOS et al., 2009);

- adaptar aos diferentes mercados os "novos conceitos de produtos" (FILIPPAIOS et al., 2009);

- internalizar os potenciais criativos específicos que se encontram espalhados por todo o globo, uma vez que a diversidade local é vista como uma fonte de desenvolvimento de ativos complementares e de exploração de oportunidades e não uma "limitação" da ação das GCTs (ZANFEI, 2000; FILIPPAIOS et al., 2009);

- capturar conhecimento com características "context-specific", mas altamente complementar ao conhecimento da corporação, o que deve permitir desenvolver conhecimento geral e abstrato aplicável em qualquer ponto da rede (ARORA; GAMBARDELLA, 1994).

A cooperação tecnológica transnacional, embora faça parte das estratégias de internacionalização da P\&D, tem sido a menos estudada (ARCHIBUGI; IAMMARINO, 1999). As razões para isto se encontram, fundamentalmente, na escassez de fontes de informação que permitam aplicar os indicadores adequados. Assim, a maior parte dos trabalhos sobre internacionalização da cooperação segue metodologias baseadas em pesquisas específicas a setores, grupos de empresas ou estudos de caso. No entanto, é cada vez maior o uso de dados de patentes para analisar os processos de internacionalização e de formação de competências no nível nacional e da empresa, possibilitando uma abordagem metodológica extensível ao estudo da cooperação internacional. Neste sentido, o presente trabalho tem como objetivos: definir uma metodologia a partir de dados de patentes que permita identificar as estratégias de cooperação tecnológica transnacional no nível nacional; e determinar e comparar as estratégias de cooperação dominantes de Estados Unidos e Japão de acordo com essa metodologia.

\section{Motivos para a internacionalização tecnológica}

A literatura inicial sobre internacionalização tecnológica, inspirada no modelo de Vernon (1966) sobre o ciclo de vida do produto, entendia que a atividade tecnológica das subsidiárias fora das fronteiras nacionais do seu país de origem deveria estar limitada à realização de alguma $\mathrm{P} \& \mathrm{D}$ adaptativa que permitisse prolongar o ciclo de vida de um produto já esgotado nos mercados domésticos, o qual não as deveria configurar como inovadoras em sentido estrito (RUGMAN, 1981). 
A teoria eclética sobre investimento estrangeiro direto contribuiu posteriormente para esta discussão, combinando a teoria do ciclo de vida do produto com a teoria dos custos de transação e incorporando a ideia de "exploração de vantagens". Para as empresas internacionalizarem recursos tecnológicos seria preciso que existissem "vantagens de propriedade" (aquelas que a empresa desenvolve em seu país de origem), "vantagens no país hospedeiro" (aquelas que fazem referência a uma melhor disponibilidade relativa de recursos tecnológicos) e "vantagens de internalização" (as que tornam preferível a realização interna frente a outras possibilidades como a subcontratação ou a compra) (DUNNING, 1979; 1994).

A partir dos anos 1990, a evidência empírica levou a outra reflexão sobre os motivos da internacionalização de $\mathrm{P} \& \mathrm{D}$, em função das novas características que o processo ia adquirindo. A visão sobre o papel das subsidiárias passou a ser de "um agente que captura competências". Sob esta nova perspectiva, parece existir um claro consenso na literatura de que a internacionalização da P\&D obedece a dois conjuntos de motivações (PEARCE, 1992; SERAPIO; DALTO, 1993; CANTWELL, 1995; DUNNING, 1994; GERYBADZE; REGER, 1999; MEYER-KRAMER; REGUER, 1999; BLANC; SIERRA, 1999; LE BAS; SIERRA, 2002; CANTWELL; IAMMARINO, 1998). De um lado, existem forças por parte da demanda que consistem em: oferecer suporte técnico às plantas de produção localizadas no exterior (interação P\&D e produção, especialmente importante em campos técnicos altamente dinâmicos); atender aos requerimentos governamentais dos países de destino (específicas regulamentações, estabelecimento de desenhos dominantes, etc.); adaptar o conhecimento doméstico às necessidades dos usuários ou dos mercados locais; e aproveitar as possibilidades de aprendizado decorrentes de atuar em mercados líderes.

De outro lado, há motivações procedentes da oferta, isto é, das possibilidades de aproveitar vantagens tecnológicas no país de destino que permitam a diversificação em novos produtos e tecnologias. Estas vantagens tecnológicas geralmente consistem em infraestrutura científica e tecnológica e "centros de excelência" que podem ser aproveitados pelas grandes corporaçōes transacionais mediante o monitoramento e acesso a resultados relevantes, o qual tem um forte componente estratégico. Esta última motivação explica porque a atividade em P\&D no exterior ainda se concentra em poucas localidades, geralmente em torno de centros de excelência da tríade. Ambas as motivaçôes podem coexistir e, de fato, coexistem em corporações que operam com cadeias de valor agregado globais (MEYER-KRAHMER; REGER, 1999) e as duas definem como uma vantagem a "proximidade locacional" no país 
de destino diante da visão tradicional de existência de vantagens de localização em torno da matriz no país de origem.

O seguimento de um ou outro tipo de motivação não é aleatório, estando, de alguma forma, vinculado aos incentivos que representam os mercados exteriores (produção, exportação ou ambos), com as características da "oferta tecnológica" do país receptor (nível de acumulação tecnológica e garantias dos direitos de propriedade intelectual -DPI) e com o processo de criação de capacidade de absorção (no sentido de COHEN; LEVINTHAL, 1989) seguido pela matriz (ITO; WAKASUGI, 2007). Os autores consideram e confirmam empiricamente para o Japão que, quanto maior o tamanho do mercado do país de destino, mais provável é que sejam empreendidas atividades de $\mathrm{P} \& \mathrm{D}$ transacional relacionadas com motivaçóes pelo lado da demanda. Se, além disso, existe uma elevada propensão a exportar, haverá incentivos adicionais para que coexistam ambos os tipos de motivação. Condiçôes favoráveis de "oferta tecnológica" do país receptor estimulam as motivações por parte da oferta, especialmente na presença de efetivos regimes de proteção intelectual. E, finalmente, quando o processo de acumulação tecnológica da corporação é elevado (maior intensidade em $\mathrm{P} \& \mathrm{D}$ ), maior será a propensão das subsidiárias em realizar P\&D de qualquer natureza. Sobre este último aspecto, têm-se identificado dois padrōes. De um lado, corporações com uma forte base de pesquisa e mercado no país de origem continuam tendo, no exterior, funções de monitoramento e exploração quanto ao desenvolvimento de aplicações (USA e Alemanha, exceto as farmacêuticas), enquanto em corporações com bases de mercado e de pesquisa menos desenvolvidas no país de origem prevalece um comportamento de concentração de competências em torno de centros de excelência (Suécia, Suíça e Holanda) (MEYER-KRAHMER; REGER, 1999).

A fronteira que distingue entre os tipos de motivação pode ser difusa. Por exemplo, uma unidade de P\&D orientada ao mercado pode dar lugar a outra orientada pela tecnologia, pois o que inicialmente é suporte técnico para transferir conhecimento desde a matriz pode se transformar em unidades de P\&D realizando pesquisa de aplicação no nível mundial (LE BAS; SIERRA, 2002). Isto significa que, em algumas ocasióes, o Desenvolvimento pode ir acompanhado de Pesquisa e, em outras, não (VON ZEDTWITZ; GRASSMANNB, 2002)

Com a chegada do terceiro milênio, um novo motivo foi incorporado. Segundo Lööf (2009), a complexidade organizacional que teve lugar para dar conta de modelos cada vez mais descentralizados levou à incorporação de um terceiro elemento sobre os motivos da internacionalização da P\&D, que é a necessidade de estabelecer 
acordos cooperativos com agentes externos, que permitam fazer um melhor uso do seu investimento em $\mathrm{P} \& \mathrm{D}$. O autor define assim três tipos de motivos para "R\&D collaboration": aquele conduzido pela demanda, que ocorre quando a P\&D é adaptativa, quando há motivos para a busca tecnológica no país de destino e quando a empresa precisa desenvolver conhecimento sobre produtos, consumidores, mercados, novos conceitos, etc.; aquele conduzido pela oferta, que acontece quando a empresa realiza atividades de P\&D para mercados globais, quando pretende aumentar o seu conhecimento-base doméstico ou quando busca desenvolver conhecimento científico sobre princípios básicos; e o conduzido conjuntamente pela oferta e a demanda, isto é, quando a empresa desenvolve P\&D dirigida a mercados locais, pretende explorar seu conhecimento base ou desenvolver soluções técnicas.

\subsection{A internacionalização de P\&D nos Estados Unidos}

Os Estados Unidos são o país que mais internacionaliza P\&D do mundo, especialmente em tecnologias intensivas em P\&D, em que são líderes tecnológicos (PATEL; VEGA, 1999; LE BAS; SIERRA, 2002). A atividade de internacionalização da P\&D iniciou-se nos Estados Unidos no final da década de 1960, tendo aumentado progressivamente nos últimos 30 anos como consequência da evolução da estrutura organizativa das grandes corporaçôes (ZANFEI, 2000; GRANDSTAND et al., 1993; CANTWELL, 1995; DUNNING, 1994; FLORIDA, 1997). No entanto, a parcela total de P\&D realizada fora do país de origem é muito menor do que aquela empreendida no país. O estudo de Cantwell e Janne (2000) identificou que, entre 1977 e 1979, apenas 11,1\% das patentes depositadas por corporaçóes norte-americanas eram realizadas fora do país de origem, proporção que cresceu para 16,2\% no período de 1987 a 1995. Investigações mais recentes feitas pelo Bureau of Economic Analisys sobre as operações das empresas transnacionais no exterior, para 1989, 1994 e 1999, mostram que o investimento em P\&D realizado pelas empresas no exterior mais que dobrou de 1989 para 1999, passando de US\$ 7.048 milhóes para US\$ 18.144 milhões (Tabela 1). A participação deste investimento sobre o montante dos gastos de P\&D da multinacional passou de $11,8 \%$ para $14,3 \%$, no mesmo período.

A distribuição dos gastos em $\mathrm{P} \& \mathrm{D}$ entre as filiais indica que os países em desenvolvimento (como países hospedeiros) aumentaram sua importância relativa ao longo dos anos: em 1989, respondiam por apenas 5,2\% do total de gastos de P\&D das filiais de transnacionais dos Estados Unidos, ampliando para 15, 1\% em 
1999. Os países em desenvolvimento foram discriminados em dois blocos: América Latina e Ásia. Os dois grupos de países possuem trajetórias distintas nos gastos das filiais em P\&D. Ambos aumentaram sua participação até 1994, embora na Ásia tenha ocorrido num ritmo mais acelerado do que na América Latina entre 1989 e 1994. Neste último ano, a participação da P\&D das filiais da América Latina era superior à da Ásia. Entre 1994 e 1999, a América Latina perdeu sua importância relativa e a parcela do investimento em P\&D reduziu-se para 3,4\% do total, enquanto a Ásia prosseguiu com trajetória de crescimento, alcançando 7,7\% do total (HIRATUKA, 2005).

TABELA 1

Evolução do gasto transnacional de P\&D das multinacionais americanas - 1989-1999

Em US\$ milhões correntes

\begin{tabular}{l|c|c|c}
\hline \multirow{2}{*}{ Empresas } & \multicolumn{3}{|c}{ Gastos em P\&D } \\
\cline { 2 - 4 } & $\mathbf{1 9 8 9}$ & $\mathbf{1 9 9 4}$ & $\mathbf{1 9 9 9}$ \\
\hline Total & $\mathbf{5 9 . 9 2 5}$ & $\mathbf{9 1 . 5 7 4}$ & $\mathbf{1 2 6 . 2 9 1}$ \\
Realizados nas filiais & 7.048 & 11.877 & 18.144 \\
Participação das filiais no total (\%) & 11,8 & 13,0 & 14,4 \\
\hline
\end{tabular}

Fonte: Bureou of Economic Analisys. Elaboração Neit/IEL/Unicamp. Adaptado de Hiratuka (2005).

A literatura chama a atenção para a centralização da internacionalização da P\&D em países da Europa (Reino Unido, Alemanha, Suíça, França, Holanda e Suécia), Estados Unidos, Japão e Canadá (PATEL; VEGA, 1999; CASSIOLATO et al., 2001; MEYER-KRAHMER; REGUER, 1999). No entanto, as empresas norte-americanas não restringiram a internacionalização dos gastos em $\mathrm{P} \& \mathrm{D}$ aos países da tríade. O deslocamento de atividades tecnológicas aos países em desenvolvimento, ainda que com ritmo vagaroso, tem crescido ao longo dos anos. $\mathrm{Na}$ segunda metade da década de 1990, os países da Ásia atraíram maiores investimentos em P\&D de filiais de empresas transnacionais norte-americanas, principalmente na China, Cingapura e Hong-kong (HIRATUKA, 2005). As características comuns a estes países são as políticas tecnológicas ativas direcionadas à geração de vantagens locais importantes, que viabilizam atividades de elevado conteúdo tecnológico. As empresas encontram nestes países mão de obra qualificada, educação técnica e superior, suporte à pesquisa básica, financiamento e incentivos às atividades de $\mathrm{P} \& \mathrm{D}$, possibilitando aumentar o grau de complementaridade e integração com empresas e instituiçōes locais (UNCTAD, 2002; LALL, 2000; 2003; HIRATUKA, 2005). 
Os setores em que as empresas norte-americanas internacionalizam mais a P\&D são, sobretudo, nos industriais químico, farmacêutico, máquinas e equipamentos, computadores, dispositivos eletrônicos, telecomunicações e farmacêutico. Trata-se, em geral, de indústrias intensivas em conhecimento científico. A internacionalização da P\&D envolveu, em $80 \%$ dos casos, o desenvolvimento de competências tecnológicas nas quais as empresas norte-americanas estavam especializadas. Em 52,3\% dos casos, o país hospedeiro também tinha vantagem tecnológica e, em 44\%, ambos (multinacional e países de acolhimento) possuíam especialização técnica (PATEL; VEGA, 1999).

O trabalho posterior de Le Bas e Sierra (2002) incluiu uma seleção de empresas norte-americanas com maior volume de patentes fora do seu país de origem. Os resultados obtidos não são muito diferentes dos apresentados por Patel e Vega (1999). Os campos técnicos em que mais houve atividade de internacionalização tecnológica foram os de transportes, eletrodomésticos e bens de consumo, componentes mecânicos, processos químicos (petróleo) e componentes eletroeletrônicos. Nestes setores, as empresas internacionalizavam P\&D em campos técnicos em que possuíam vantagens domésticas, como tecnologias da informação, processos químicos e química do petróleo.

As empresas norte-americanas têm buscado, por meio da internacionalização, capturar competências que são fracas em seu país (ou estratégia technology-seeking), como, por exemplo, em tecnologias de transporte (LE BAS; SIERRA, 2002). As empresas norte-americanas teriam desenvolvido atividades tecnológicas no exterior com vantagens tecnológicas em $85 \%$ dos casos; $60 \%$ da internacionalização da P\&D ocorreria em países de acolhimento onde também havia especialização e, em 51\% dos casos, ambos os países (Estados Unidos e o país hospedeiro) teriam vantagem tecnológica doméstica (home-base-augmenting). Estes resultados reforçariam ainda mais os documentados por Patel e Vega (1999).

\subsection{A internacionalização de P\&D no Japão}

A expansão da P\&D transnacional no Japão foi observada desde o início da década de 1990. Já no final dos anos 1980, o governo japonês alocava 4/5 do orçamento de P\&D em projetos de colaboração tecnológica (ERBER; CASIOLATO, 1997). Em 1989, a parcela de P\&D japonês investida no exterior correspondia a apenas $0,7 \%$ do total de investimento gasto domesticamente. Esta porcentagem elevou-se até 4,2\% em 2002. As empresas japonesas aumentaram seus gastos em P\&D no 
exterior de um valor de 2,1 bilhões de dólares, em 1995, para 3,3 bilhōes, em 2000 (ITO; WAKSUGI, 2007). No entanto, Japão é o país que menos internacionaliza dentre os que compõem a tríade (LE BAS; SIERRA, 2002; PATEL; VEGA, 1999; MEYER-KRAHMER; REGER, 1999).

$\mathrm{Na}$ média, entre 1996 e 2001, as indústrias japonesas que mais internacionalizaram P\&D foram: química, alimentícia, equipamentos de transporte, equipamentos elétricos, maquinaria em geral e maquinaria de precisão. A maior parcela do investimento em P\&D no exterior ocorreu nas indústrias química e alimentícia, esta última atribuída ao investimento em biotecnologia. As indústrias de equipamentos de transportes desempenharam um notável aumento entre 1996 e 2001, devido à expansão dos centros de $\mathrm{P} \& \mathrm{D}$ das automobilísticas, Toyota e Honda, nos Estados Unidos e na Europa, assim como pela instalação de novos centros na Ásia, principalmente na China e na Tailândia, com o objetivo de ampliar seus mercados (SHIMIZUTANI; TODO, 2008). As principais tecnologias em que tem ocorrido a internacionalização são biotecnologia, armamento espacial, alimentos e produtos agrícolas, tecnologia da informação, transportes (LE BAS; SIERRA, 2002), máquinas, computadores e imagem e som (PATEL; VEGA, 1999), envolvendo tanto campos técnicos de elevada especialização em Japão (caso de tecnologias de informação), como outros em que não há especialização (farmacêutica, cosmética e armamento espacial).

O Japão realiza internacionalização de $\mathrm{P} \& \mathrm{D}$ tanto em pesquisa básica quanto em pesquisa aplicada e/ou no desenvolvimento/elaboração de projetos. Os tipos de internacionalização de $\mathrm{P} \& \mathrm{D}$ não são excludentes e a maioria das empresas subsidiárias japonesas localizadas no exterior realiza diferentes atividades de inovação (SHIMIZUTANI; TODO, 2008). Os autores identificaram que as empresas multinacionais - EMN japonesas são mais propensas a internacionalizar P\&D de tipo aplicado quando os gastos de P\&D sobre o PIB do país hospedeiro são altos, ou seja, quando o nível de conhecimento do país de acolhimento é maior. No entanto, essa taxa não influencia a $\mathrm{P} \& \mathrm{D}$ orientada a desenvolvimento. Seus resultados são consistentes com a literatura, pois confirmam que a $\mathrm{P} \& \mathrm{D}$ orientada pela pesquisa básica (fator de oferta) visa explorar o conhecimento do país anfitriáo, enquanto aquela orientada pelo desenvolvimento (fator de demanda) é influenciada pelas características do mercado. Outros fatores que também influenciam a internacionalização da P\&D são a relação entre gastos de P\&D e vendas da multinacional, a distância de Tóquio, o salário dos engenheiros e o desempenho das vendas das filiais ao longo dos anos. 
Até o início da década de 1990, a localização da P\&D internacionalizada pelo Japão concentrava-se em economias mais avançadas (América do Norte e Europa), com o objetivo de monitoramento da evolução tecnológica (ODAGIRI; YASUDA, 1996). Mas ao longo das duas últimas décadas, as empresas japonesas estenderam suas atividades a países em desenvolvimento e de industrialização recente, sobretudo na Ásia ocidental (SHIMIZUTANI; TODO, 2008). A literatura aponta que os principais países hospedeiros são os Estados Unidos, Coreia do Sul, Taiwan, Grã-Bretanha, França, China, Alemanha, Malásia e Holanda, onde a internacionalização da P\&D é do tipo pesquisa básica. Aproximadamente metade da internacionalização realizada na Grã-Bretanha, Estados Unidos e Coreia do Sul está comprometida com atividades de pesquisa básica, enquanto na França, Malásia, Singapura, China e Taiwan apenas $40 \%$ da P\&D corresponde a esse tipo. Em outros países, como Austrália e Ásia Ocidental (Hong-Kong, Indonésia, Filipinas, Singapura e Tailândia), onde os motivos da internacionalização estão vinculados à busca de novos mercados, a parcela da P\&D é baixa (SHIMIZUTANI; TODO, 2008). Na metade da década de 1990, a internacionalização cresceu para todos os países que se situam na fronteira tecnológica, enquanto na Ásia aumentou apenas na China, Hong-Kong e Singapura. A intensidade dos gastos de P\&D transacional tem sido maior nos países da fronteira tecnológica (aproximadamente 79\%), sendo que na Ásia representa apenas $10 \%$. No entanto, em países como Coreia do Sul e Taiwan, a intensidade em $P \& D$ transnacional chega a ser similar à de países da fronteira tecnológica, o que induz a pensar que, nestes países, a internacionalização é determinada não somente pela busca de novos mercados, mas também pela possibilidade de capturar competências e oportunidades tecnológicas (SHIMIZUTANI; TODO, 2008).

A distribuição geográfica da P\&D transnacional segue as estratégias de internacionalização "novos mercados" e/ou "vantagens tecnológicas". O desenvolvimento de projetos no exterior é executado, geralmente, com conhecimento da matriz, apenas adaptando tecnologia e produto existentes à cultura e padrão do país hospedeiro. A internacionalização motivada pelo monitoramento de novos avanços tecnológicos depende do nível de conhecimento do país anfitrião. As subsidiárias envolvidas em atividades de pesquisa tendem a se concentrar em países que se situam na fronteira tecnológica pela sua dimensão econômica e tecnológica, particularmente nos Estados Unidos. O nível de conhecimento desses países compensa a desvantagem da distância. Uma parte das filiais desempenha atividades de pesquisa também na Coreia do Sul e Taiwan, devido ao alto nível tecnológico e à proximidade geográfica do Japão. Por 
fim, a expansão de subsidiárias japonesas na China responde à dinamicidade do seu crescimento econômico (SHIMIZUTANI; TODO, 2008; GRANSTRAND, 1990; IWASA; ODAGIRI, 2004; ODAGIRI; YASUDA, 1996).

O trabalho de Shimizutani e Todo (2008) identificou que, nas empresas japonesas: a intensidade em $\mathrm{P} \& \mathrm{D}$ se relaciona positivamente com a internacionalização; quanto maior o volume de vendas das filiais e os anos de operação no país de acolhimento, maior e significativa é a influência no investimento em P\&D; quanto maior a intensidade em $\mathrm{P} \& \mathrm{D}$ do país hospedeiro, maior é a propensão a desenvolver pesquisa básica; a distância de Tóquio ao país anfitrião é negativamente relacionada com a probabilidade de realizar P\&D; ${ }^{1}$; e o rendimento médio dos engenheiros do país hospedeiro afeta negativamente a probabilidade de realizar pesquisa básica nele. Resultados semelhantes foram obtidos por Ito e Wakasugi (2007): a parcela de vendas das filiais no país de destino tem efeito positivo sobre a expansão dos gastos de P\&D; a abundância de recursos humanos e o nível de acumulação tecnológica do sistema de inovação nacional de casa do país de destino são motivos para a expansão de $\mathrm{P} \& \mathrm{D}$, ou seja, países e empresas especializadas tecnologicamente são fatores importantes para o alargamento de P\&D transnacional; e a maior aplicação dos direitos de propriedade nos países hospedeiros expande as fontes de conhecimento em P\&D das empresas para o exterior.

Além destes fatores, o tamanho de mercado do país de acolhimento tem efeito positivo sobre o volume dos gastos em P\&D em EMN norte-americanas e japonesas (KUMAR, 2001), embora outros estudos contradissessem estes resultados (PAPANASTASSIOU; PEARCE, 1995). O resultado sobre abundância de recursos humanos é ainda apoiado pelo trabalho de Kumar (2001), que mostrou que os países com maior proporção de cientistas e engenheiros influenciam positivamente as despesas de $\mathrm{P} \& \mathrm{D}$ das filiais de empresas norte-americanas e japonesas, enquanto salários elevados do pessoal envolvido em P\&D têm efeito negativo.

Em termos de estratégias, os principais trabalhos realizados para o caso japonês revelam resultados contrapostos. Patel e Vega (1999) identificaram que 53,8\% das estratégias envolviam campos técnicos nos quais o Japão possuía vantagens tecnológicas, mas os países anfitriōes não estavam especializados (bome-base-exploiting) e só $26,9 \%$ dos casos de internacionalização correspondiam a áreas técnicas em que ambos os países eram especializados (home-base-augmenting). Já o trabalho de Le Bas e Sierra (2002) identificou o contrário. A porcentagem maior corresponde

1 A distância de Tóquio a Coreia do Sul é de 1.200 km, enquanto para os Estados Unidos é de $10.100 \mathrm{~km}$. Isso aumenta a probabilidade de investimento de P\&D básica em quase $11 \%$ na Coreia do Sul. 
à estratégia em que ambos os países possuem competências técnicas domésticas (35,3\%), enquanto a estratégia home-base-exploiting concentraria $32,1 \%$ dos resultados. A justificativa para tais divergências podem estar nas diferenças nas bases de dados. Patel e Vega (1999) extraíram os dados da USPTO (Oficina Americana de Patentes), enquanto Le Bas e Sierra (2002) utilizaram dados da EPO (Oficina Europeia de Patentes).

\section{Bases de dados}

A base de dados de cooperação tecnológica para os Estados Unidos e Japão foi construída a partir do levantamento das patentes depositadas na EPO (European Patent Office) por, no mínimo, dois depositantes e em que pelo menos um deles registrou residência em cada um dos países contemplados.

A utilização de patentes para analisar processos de internacionalização tem crescido nos últimos anos (PATEL; VEGA; 1999; LE BAS; SIERRA, 2002; MA; LEE, 2008). As patentes podem ser também utilizadas como indicador de cooperação tecnológica porque representam o resultado (intra ou extramuros) de um esforço em pesquisa, além do fato de a existência de mais de uma pessoa jurídica sem vínculo de propriedade como depositantes das patentes caracterizar que há algum tipo de cooperação.

No entanto, alguns autores fazem uso de informações sobre colaborações disponíveis em publicações de jornais e revistas especializados ou de questionários aplicados nas empresas de inovação (HAGEDOORN, 1991; BEERS et al., 2008). Essas bases de dados são limitadas, pois existem diferentes propensões à cooperação entre empresas, setores e países. A colaboração entre empresas de específicas nacionalidades pode ser superestimada ou subestimada, devido à importância atribuída pelos periódicos de publicaçóes em favor de áreas específicas de atuação ou do público-alvo.

Desta forma, as patentes são, ainda, vistas como uma medida mais homogênea quando comparadas com divulgações em jornais especializados. As patentes, pelo seu caráter ex-post, não cometem o erro de contar como colaboração esforços ainda não realizados. Entretanto, existem algumas deficiências quanto ao seu uso (ROCHA, 1995), tais como: os dados de patentes limitam-se à análise de atividades de P\&D que podem ser patenteadas, o que significa que as patentes não refletem devidamente esforços de cooperação em $\mathrm{P} \& \mathrm{D}$ em setores que geram tecnologias não patenteáveis (por exemplo, software, sujeito às leis de copyright) ou onde as 
patentes não representam uma forma efetiva de proteção; ${ }^{2}$ as patentes não captam cooperação tecnológica não-inovadora, como no caso de esforços em transferência tecnológica; e, como não existe uma forma homogênea de cooperação, pode haver casos de cooperação conhecidos como joint-venture ${ }^{3}$ (sociedade comum ou consórcio), que não fazem parte da base de dados ou que passem despercebidos. Num processo cooperativo do tipo joint venture, pode acontecer que os resultados patenteados fiquem sob o nome da unidade autônoma (da joint venture). Neste caso, a patente é classificada como individual e, definitivamente, não constará na base de dados como cooperação. Se aparecer sob o nome das empresas proprietárias, a patente será definida como cooperação entre empresas que compõem a joint venture, mas passará despercebido, na análise dos dados, que se trata de resultado de uma joint-venture.

A base de dados do EPO oferece algumas vantagens em relação à do USPTO (United States Patent and Trademark Office). Em primeiro lugar, o EPO é uma base de dados mais internacionalizada, ${ }^{4}$ pois cada aplicação pode ser potencialmente estendida a todos os países signatários da Convenção de Munique (LE BAS; SIERRA, 2002), enquanto as depositadas no USPTO têm validade somente em território americano. Este fato pode gerar um viés na análise estatística dos padrões de atividade tecnológica, superestimando os dados para os Estados Unidos. Na análise de Estados Unidos e Japão, o EPO funciona com um escritório estrangeiro, o que reduz o problema de viés nacional dos registros. Ademais, o EPO publica as patentes depois de 18 meses de sua aplicação, enquanto o USPTO o faz em 24 meses, ou seja, o EPO permite trabalhar com dados mais atualizados (LE BAS; SIERRA, 2002).

As patentes em cooperação foram selecionadas para o período de 1985 a 2008. As informaçôes obtidas para cada patente são: nome do depositante; nacionalidade do depositante; código de registro das patentes; campo técnico de acordo com a Classificação Internacional de Patentes (IPC); período; número de nacionalidades (residência) dos inventores envolvidos; e nome e nacionalidade dos parceiros. A partir destas informações, a base passou por um processo de

2 As patentes são apenas uma forma de proteção, mas existem outras destacadas por Levin et al. (1997), como o segredo, know-how ou os tempos de liderança. A importância relativa de cada forma de apropriação varia entre setores e tecnologias.

3 Aliança estratégica entre duas ou mais empresas, instituindo uma companhia legalmente independente a fim de compartilhar alguns dos seus recursos e capacidades para desenvolver vantagens competitivas (ZANFEl, 2000).

4 O EPO não tem viés nacional (OST, 1998:506; Le Bas e Sierra, 2002).

5 Tratou-se de um acordo multilateral que estabeleceu um sistema jurídico de patentes unificado e aplicável para seus 15 países membros. 
tratamento dos dados. Só foram examinados registros que representam Depósitos em Conjunto (DC), isto é, patentes com mais de um depositante. Os DC entre empresas com vínculo de propriedade foram eliminados, pois a literatura não as considera cooperações em sentido estrito. Em numerosas ocasiōes, várias subsidiárias patenteiam conjuntamente como parte da estratégia global de patenteamento das grandes corporaçôes, sem que isso necessariamente signifique envolvimento cooperativo entre as partes envolvidas.

Para cada patente foram adicionadas informaçôes na forma de três variáveis: a codificação de campos técnicos equivalente à classificação setorial da NACE (Statistical Classification of Economic Activities) para um nível de desagregação de 44 setores industriais, ${ }^{6}$ seguindo a metodologia de Schmoch et al. (2003); sua condição de nacional ou internacional, caso a nacionalidade da parceira só contasse com parceiros e inventores nacionais, ou se algum inventor ou parceira tivesse nacionalidade diferente das relativas aos países em estudo, respectivamente; e a qualificação da cooperação em função do tipo de parceiro, diferenciando entre cooperaçôes que só envolvem empresas nacionais, as que englobam empresas nacionais e internacionais e as que incluem empresas e centros públicos de pesquisa nacionais ou internacionais.

Os campos técnicos estão classificados segundo IPC (classificação internacional das patentes), em termos de categoria tecnológica, pelo qual não podem ser diretamente interpretados como "setor industrial". Para tal, foi realizada uma relação confiável entre tecnologia e indústria, por meio da recodificação do IPC à NACE. A seleção de setores industriais foi feita a dois dígitos da NACE, o que constitui um total de 44 .

\section{Motivações e estratégias de cooperação nos Estados Unidos e Japão}

A análise comparativa das estratégias de internacionalização da cooperação tecnológica entre Estados Unidos e Japão será realizada em duas fases. Em primeiro lugar, mediante um exercício aplicado da Teoria de Grafos, serão identificados os principais parceiros nas relações de cooperação transnacional nos Estados Unidos e Japão. Em seguida será desenvolvida uma metodologia, a partir de dados de patentes, que será aplicada sobre as relações de cooperação tecnológica transnacional de ambos os países com seus principais parceiros.

6 Código NACE - Nomenclature of Economic Activities in the European Community. 


\subsection{Redes de cooperação transnacional e centralidade dos principais parceiros}

A centralidade dos países parceiros dentro da rede de cooperantes que cada país estabelece foi estimada a partir 0de medidas de centralidade de grau e de autovetor provenientes da Teoria de Grafos. A centralidade estabelece qual a posição que os países parceiros ocupam na rede de cooperação internacional e, como consequência, identifica os principais parceiros de cada país.

Formalmente, se define $G(V, E)$ como um grafo simples, não orientado, em que $V$ é um conjunto finito e não vazio formado por n vértices, tal que $v_{i} \in V$ e $E$ é um conjunto de subconjuntos de dois elementos de $V$, cujos elementos são denominados arestas, tal que $\left(v_{i,}, v_{j}\right) \in E$. Uma sequência de graus de vértice se define como $\Delta=d\left(v_{1}\right) \geq d\left(v_{2}\right) \geq \cdots \geq d\left(v_{n,}\right)=\delta$ para $i \neq j ; i, j=1, \ldots \ldots . n$ (DEL VECCHIO et al., 2009). O grau de um vértice $v$, denotado por $d(v)$, corresponde ao número de arestas que incidem em $v$; e os vértices ligados por arestas são ditos vértices adjacentes. Uma das formas de representar (ou construir) um grafo $\mathrm{G}=$ $\mathrm{G}(\mathrm{V}, \mathrm{E})$ com n vértices é por meio de uma matriz de adjacência de $G$. Esta matriz toma valores 1 ou 0 , de acordo com a existência ou não de relação de adjacência, respectivamente, entre os vértices dos grafos. A matriz adjacência $A(G)$ é definida como uma matriz quadrada de ordem $n$ e simétrica, cujas entradas são:

$a_{i, j}-\left\{\begin{array}{c}1, \text { se }\left\{v_{i}, v_{j}\right\} \in \text { E para } v_{i}, v_{j} \in \mathrm{V} \\ 0, \quad \text { outros casos }\end{array}\right.$

Ou seja, a entrada será igual a 1 se houver uma aresta ligando o par de vértices - caso haja cooperação entre o par de países - e zero em caso contrário (ANDRADE et al., 2007). O grau de um vértice é determinado pelo número de arestas que saem deste, ou seja, pelo número de ligaçōes que este vértice realiza; ou ainda, pela soma dos elementos da linha da matriz de adjacência (FEOFILOFF, 2006).

As medidas de centralidade em grafo são utilizadas para mensurar a importância relativa de determinado vértice (país). Neste trabalho, foram empregados dois tipos: a centralidade de grau, calculada mediante a soma do número de interações de um dado país com os demais da rede; e a centralidade de autovetor, que classifica um país como mais central à medida que este se relaciona com outros países que também estão em uma posição central (RUHNAU, 2000 apud DEL VECCHIO 
et al., 2009), sendo uma medida de influência indireta somada às influências diretas (DEL VECCHIO et al., 2009). A centralidade de autovetor de um país é uma combinação linear dos países a ele associados, ou seja, à centralidade de um país adicionam-se as centralidades dos que a ele estão conectados. A ideia subjacente é que a importância de determinado vértice depende da posição que o vizinho ocupa em todo o grafo (BONACICH, 2001). Matematicamente, a matriz de adjacência fornece um polinômio característico dado por:

$$
p G=\operatorname{det}(A(G)-\lambda I)
$$

onde $\lambda_{1} \geq \lambda_{2} \geq \ldots \lambda_{n}$ são os autovalores associados a $G$. A centralidade de autovetor corresponde à coordenada de autovetor associada ao maior autovalor (ALVES et al., 2008).

A centralidade de grau é uma medida direta de centralidade e está estreitamente relacionada com o conceito de grau de vértice. Esta é uma medida do número de interações e conexões diretas realizado por determinado vértice com os demais. Dada a matriz de adjacência de um grafo associado, a centralidade de grau de um vértice $v_{i} v_{i}$ é obtida pela soma dos valores da linha ou coluna associada a este vértice. A representação formal da medida de centralidade de grau (DEL VECCHIO et al., 2009) é:

$$
C d\left(v_{i,}\right)=d\left(v_{\mathrm{i}}\right)=\sum_{j=1}^{n} a_{i j} \text { onde }_{i} \in V
$$

A matriz de adjacência representa relaçóes binárias entre países, tomando valores 1 ou 0 , dependendo se é importante ou não na rede e independentemente do número de cooperaçôes existente entre ambos os países. Para construir as matrizes de adjacência foram selecionadas apenas as cooperaçôes de caráter internacional. A partir daí, foram construídas matrizes de $n \times n$ países, de acordo com as nacionalidades de cada cooperante até um total de seis tabelas $\left(A_{1} \ldots . . A_{6}\right)$. A matriz $A_{1}$ representa as relaçóes entre $2^{\circ}$ e $3^{\circ}$ depositantes, a matriz $A_{2}$ é estabelecida entre $3^{\circ}$ e $4^{\circ}$ depositantes e a matriz $\mathrm{A}_{3}$ é a relação entre $2^{\circ}$ e $4^{\circ}$ depositantes. As demais matrizes são construídas a partir das relações inversas na ordem dos depositantes das três primeiras matrizes. As tabelas foram somadas em uma matriz quadrada simétrica, que agrega o total de inter-relaçôes entre os países envolvidos nas cooperações internacionais (matriz A - EUA; matriz B - JP). O número de países cooperantes com os Estados Unidos foi de 62 e com o Japão correspondeu a 40. 
Para o cálculo das centralidades de grau e autovetor, é preciso calcular previamente a matriz de adjacência, a qual se constrói aplicando um parâmetro de exclusão nas matrizes A e B, que permite transformar estas matrizes em matrizes binárias (com valores zero ou um), sendo fundamental para o cálculo das medidas de centralidade de grau e de autovetor. O parâmetro de exclusão escolhido foi $\frac{c_{j} c_{j}}{I_{j} I_{j}}$, onde $C_{j}$ representa o total de cooperações internacionais do país j e $I_{j}$ corresponde ao total de inter-relações do país $\mathrm{j}$. Este parâmetro expressa a média da cooperação internacional por número de inter-relações dos países envolvidos nas parcerias com os Estados Unidos e o Japão. O parâmetro que se impõe aos pares de países para que eles recebam arestas é que possuam um número de cooperações internacionais por inter-relação maior ou igual a 3,88 para os Estados Unidos e 4,0 para o Japão. A matriz de adjacência foi montada sobre a condição de tomar valor 1 , se o número de cooperações por países for superior a 4, e zero no caso contrário. O grafo foi construído a partir desta matriz de adjacência, em que cada país representa um vértice e o número de cooperações acima da média estabelecida representa uma aresta entre o par de países.

As Figuras 1 e 2 representam os grafos para Estados Unidos e Japão, respectivamente. A Figura 1 mostra os países com os quais os Estados Unidos cooperaram ("caixinhas" numeradas), assim como a interligação entre países (arestas). O país interligado via aresta possui maior importância relativa no grafo, pois passou pelo crivo do critério de exclusão. Os Estados Unidos (código 59) são o país que está mais interligado aos demais países, tendo maior importância França, Grã-Bretanha, Suíça, Alemanha, Austrália, Holanda, Canadá, Dinamarca, Japão, Ilhas Virgens (Britânica), Austrália, Bélgica e Itália.

De acordo com a centralidade de grau, os Estados Unidos aparecem como um país central dentro de sua própria rede, ou seja, suas cooperaçôes internacionais envolvem no mínimo dois depositantes nacionais. Este efeito deve-se a vários motivos. Em primeiro lugar, existem casos em que as filiais de multinacionais estrangeiras nos Estados Unidos operam com mais de um agente americano (empresa, universidade ou instituto de pesquisa) na formação de uma rede externa. Em segundo lugar, este é o efeito de ter definido o caráter internacional da cooperação a partir da nacionalidade do inventor ou do depositante. Desta forma, pode-se dar o caso de cooperaçôes que adquirem seu caráter internacional por contar com inventor não residente, mesmo sendo residentes todos seus depositantes. 
FIGURA 1

Cooperações internacionais dos Estados Unidos e seus principais parceiros, segundo o critério de exclusão
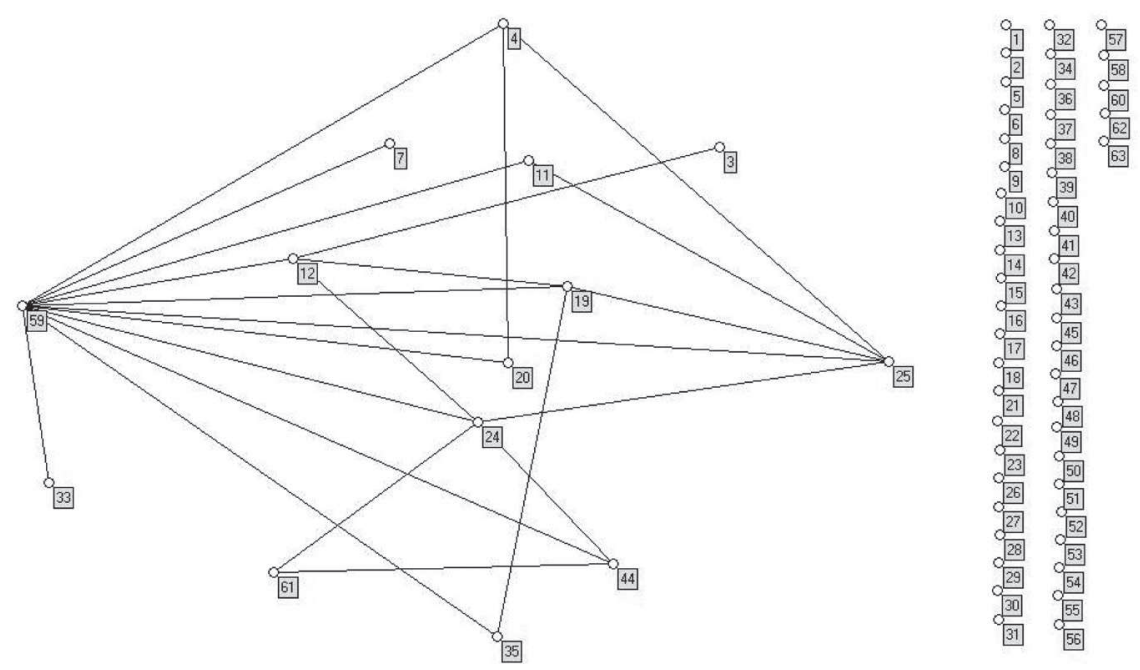

Países de maior importância no grafo: 3 - Áustria, 4 - Austrália, 7 - Bélgica, 11 - Canadá, 12 Suíça, 19 - Alemanha, 20 - Dinamarca, 24 - França, 25 - Grã-Bretanha, 33 - Itália, 35 - Japão, 44 - Holanda, 59 - Estados Unidos e 61 - Ilhas Virgens (Inglaterra).

Países excluídos após o critério de exclusão. 1 - Antilhas Holandesas, 2 - Argentina, 5 - Azerbaijão, 6 - Barbados, 8 - Bermudas, 9 - Brasil, 10 - Bahamas, 13 - Chile, 14 - China, 15 - Costa Rica, 16 - Antiga Tchecoslováquia, 17 - Chipre, 18 - República Tcheca, 21 - Egito, 22 - Espanha, 23 Finlândia, 26 - Hong-Kong, 27 - Croácia, 28 - Hungria, 29 - Irlanda, 30 - Israel, 31 - Índia, 32 - Islândia, 34 - Jordânia, 36 - Quênia, 37 - Coreia do Sul, 38 - Ilhas Cayman, 39 - Liechtenstein, 40 - Luxemburgo, 41 - Malásia, 42 - México, 43 - Namíbia, 45 - Noruega, 46 - Nova Zelândia, 47 - Polônia, 48 - Porto Rico, 49 - Portugal, 50 - Rússia, 51 - Arábia Saudita, 52 - Suécia, 53 Cingapura, 54 - Eslovênia, 55 - Antiga União Soviética, 56 - Tailândia, 57 - Taiwan, 58 - Ucrânia, 60 - Venezuela, 62 - Samoa e 63 - África do Sul -

Fonte: European Patente Office - EPO. Espace Bulletin (1985-2008). Elaboração das autoras.

A Tabela 2 apresenta as duas medidas de centralidade - de grau e de autovetor - para as cooperações internacionais dos Estados Unidos. Os países na rede americana são Grã-Bretanha, França e Alemanha. A Grã-Bretanha é o país mais importante, dado que se encontra ligado a cinco países e apresenta a maior centralidade de autovetor $(0,362)$. A França segue em ordem de importância a Grã-Bretanha, também com cinco ligações entre países, mas com centralidade de autovetor de 0,340. Em seguida vem a Alemanha, ligada a quatro países e com centralidade de autovetor igual a 0,305 . 
TABELA 2

Medidas de centralidade para os Estados Unidos

\begin{tabular}{cllcc}
\hline Código & \multicolumn{1}{c|}{ Países } & Centr. grau & Centr. autovetor \\
\hline 25 & Grã-Bretanha & 5 & 0,362 \\
24 & França & 5 & 0,340 \\
19 & Alemanha & 4 & 0,305 \\
12 & Suíça & 4 & 0,278 \\
4 & Austrália & 3 & 0,241 \\
44 & Holanda & 3 & 0,225 \\
11 & Canadá & 2 & 0,203 \\
20 & Dinamarca & 2 & 0,176 \\
35 & Japão & 2 & 0,190 \\
61 & Ilhas Virgens (Inglaterra) & 2 & 0,124 \\
3 & Áustria & 1 & 0,061 \\
7 & Bélgica & 1 & 0,123 \\
33 & Itália & 1 & 0,123 \\
- & Países excluídos & 0 & 0,000 \\
\hline
\end{tabular}

Fonte: European Patente Office - EPO. Espace Bulletin (1985-2008). Elaboração das autoras.

O Japão não aparece entre os países mais significantes nas cooperações internacionais dos Estados Unidos. A explicação para a baixa importância de acordo com sua posição no grafo é que o país estabelece parcerias apenas com os Estados Unidos e a Alemanha, o que se deriva numa pequena centralidade na rede. Já o papel de Grã-Bretanha, França e Alemanha é diferente. Na rede de cooperações que definem os Estados Unidos, esses países adquirem importante centralidade porque permitem a interconexão com outros países.

Um fato importante a ser enfatizado é que a ordenação a partir de centralidade de grau não diz tanto sobre a importância dos países no gráfico quanto a centralidade de autovetor. A diferença deve-se aos próprios conceitos destas medidas e, especialmente, porque a centralidade de autovetor leva em consideração a posição dos parceiros no grafo como um todo. Os principais países parceiros dos Estados Unidos nas cooperações internacionais, segundo a centralidade de autovetor, são Grã-Bretanha, França e Alemanha.

Para o Japão (código 24), após a aplicação do critério de exclusão, apenas nove países se apresentaram como os mais importantes parceiros nas suas cooperaçóes internacionais. São eles: Estados Unidos, Alemanha, Áustria, Suíça, Grã-Bretanha, 
Canadá, Dinamarca, Coreia do Sul e Holanda (Figura 2). A centralidade do Japão no grafo também indica a presença de, no mínimo, dois parceiros japoneses nas redes de cooperação internacional. A natureza destas parcerias pode ser de dois tipos. O primeiro ocorre quando todos os depositantes são japoneses, mas contam com inventores estrangeiros. Quando os depositantes são constituídos por universidades, centros de pesquisas e governo, a presença de Japan Science and Technology Agency (JST) como um dos depositantes é frequente. As parcerias envolvendo apenas empresas são comuns entre concorrentes e fornecedores. O segundo tipo ocorre quando os depositantes são nacionais e estrangeiros, o que corresponde à formação de redes externas. Nesse caso, são comuns acordos entre empresas concorrentes, principalmente do setor farmacêutico e eletroeletrônicos.

\section{FIGURA 2}

Cooperações internacionais do Japão e seus principais parceiros, segundo o critério de exclusão
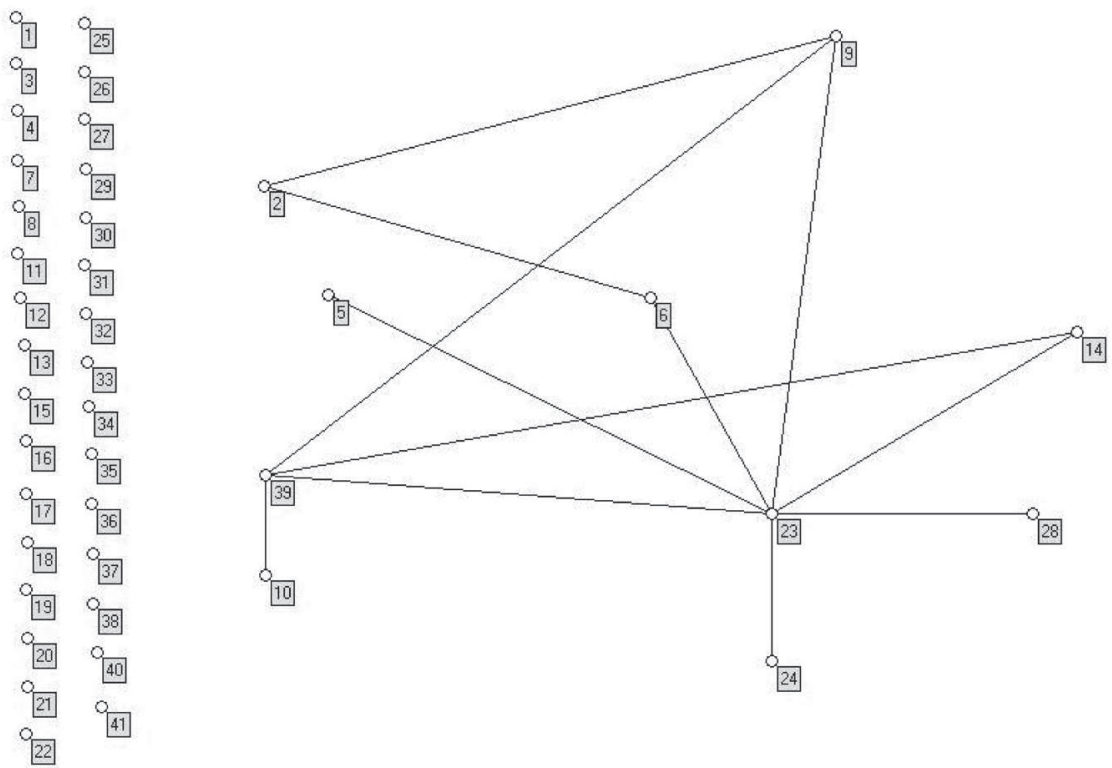

Países de maior importância no grafo: 2 - Austrália 5 - Canadá, 6 - Áustria, 9 - Alemanha, 10 Dinamarca, 14 - Grã-Bretanha, 23 - Japão, 24 - Coreia do Sul, 28 - Holanda, 39 - Estados Unidos. Países excluídos após o critério de exclusão. 1 - Antilhas Holandesas, 3 - Austrália, 4 - Bélgica, 7 - China, 8 - República Tcheca, 11 - Espanha, 12 - Finlândia, 13 - França, 15 - Grécia, 16 Hong-Kong, 17 - Hungria, 18 - Indonésia, 19 - Irlanda, 20 - Israel, 21 - Índia, 22 - Itália, 25 - Luxemburgo, 26 - Liechtenstein, 27 - Malásia, 29 - Noruega, 30 - Nova Zelândia, 31 - Filipinas, 32 - Polônia, 33 - Rússia, 34 - Suécia, 35 - Cingapura, 36 - Antiga União Soviética, 37 - Tailândia, 38 - Taiwan, 40 - Venezuela e 41 - África do Sul.

Fonte: European Patente Office - EPO. Espace Bulletin (1985-2008). Elaboração das autoras. 
Segundo as medidas de centralidade de grau e de autovetor, os países mais centrais na rede de cooperação internacional do Japão são os Estados Unidos, com até quatro interligações entre países e centralidade de autovetor igual a 0,439, e a Alemanha, apresentando interligação com até três países e centralidade de autovetor de 0,377 (Tabela 3). Em resumo, pode-se concluir que em ambos os países há relevante participação de pelo menos dois cooperantes da nacionalidade de origem na cooperação transnacional. Este comportamento sugere a formação de rede externa, como, por exemplo, cooperaçôes envolvendo a multinacional, subsidiária no estrangeiro e uma empresa concorrente, um fornecedor, uma universidade ou um centro de pesquisa nacional ou estrangeiro.

TABELA 3

Medidas de centralidade para o Japão

\begin{tabular}{r|lccc}
\hline Código & Países & Centr. grau & $\begin{array}{c}\text { Centr. } \\
\text { Autovetor }\end{array}$ \\
\hline 39 & Estados Unidos & 4 & 0,439 \\
9 & Alemanha & 3 & 0,377 \\
2 & Áustria & 2 & 0,191 \\
6 & Suíça & 2 & 0,242 \\
14 & Grã-Bretanha & 2 & 0,318 \\
5 & Canadá & 1 & 0,183 \\
10 & Dinamarca & 1 & 0,135 \\
24 & Coreia do Sul & 1 & 0,183 \\
28 & Holanda & 1 & 0,183 \\
- & Países excluídos & 0 & 0 \\
\hline
\end{tabular}

Fonte: European Patente Office - EPO. Espace Bulletin (1985-2008). Elaboração das autoras.

Sobre esta observação, três fatos chamam a atenção na comparação entre ambas as redes. O primeiro é que a rede americana inclui um maior número de países, o que, provavelmente, é consequência de os Estados Unidos contarem com maior grau de internacionalização. O segunda é que a rede de cooperação dos Estados Unidos estabelece maior número de interligações entre países do que a rede determinada pelo Japão. Este resultado sugere que o Japão estabelece relações concentrando-se num menor número de países parceiros. Os principais países parceiros das cooperações internacionais para os Estados Unidos são Grã-Bretanha, França e Alemanha, enquanto para o Japão são Estados Unidos e Alemanha. O terceiro fato é que, tanto na rede americana quanto na japonesa, os principais parceiros se encontram dentro 
da tríade, o que leva a pensar que, em ambos os casos, predominou a captura pelas competências técnicas que estes países detêm.

\subsection{Motivações e estratégias de cooperação em Estados Unidos e Japão}

Uma vez identificados os principais parceiros da rede, segundo a centralidade de autovetor, serão estudadas as principais estratégias desenvolvidas com eles. Descontados os pesos que Japão e Estados Unidos têm em suas próprias redes, os principais parceiros representam $61,3 \%$ do total das cooperações americanas e $69,2 \%$ das japonesas.

Um dos principais fatores de motivação da cooperação tecnológica internacional é a busca das competências técnicas quando internamente o país não é dotado de especialização técnica de acordo com sua dotação de recursos à inovação (por exemplo, o número de cientistas e engenheiros ou o esforço nacional público e privado em P\&D). Mas também pode acontecer a situação inversa, ou seja, é possível que os países parceiros estejam explorando as competências tecnológicas do próprio país. $\mathrm{O}$ potencial tecnológico do país parceiro na rede de cooperação chama à cooperação, dado que o principal fator orientador da cooperação de P\&D é o conhecimento científico tecnológico que pode ser obtido por meio da parceria. No entanto, existem outros fatores que influenciam a realização da cooperação, tais como as restrições financeiras, os elevados custos, riscos e incertezas para investir em P\&D.

Para quantificar as estratégias em função de um ou outro tipo de motivação, foi realizada uma taxonomia inspirada nos trabalhos de Patel e Vega (1999), Kuemmerle (1999) e Le Bas e Sierra (2002) sobre os tipos de estratégias de internacionalização de P\&D relativa a empresas. A taxonomia é construída a partir dos valores combinados, por campo técnico, da VTR doméstica da corporação ${ }^{7}$ e da VTR do país de onde a corporação realiza atividade inovadora ou utiliza recursos tecnológicos relevantes (Quadro 1).

A estratégia tipo I é denominada technology-seeking FDI in $R \& D$ ou host-country-exploiting. Este tipo de estratégia surge pela debilidade tecnológica do país de origem num determinado campo técnico, o que leva à corporação focalizar sua atividade tecnológica num país de destino que registre comprovada qualificação nesse mesmo campo técnico. A atividade tecnológica empreendida no país de destino pode tomar a forma de P\&D experimental e, se houver grande discrepância entre

7 As vantagens domésticas são calculadas utilizando apenas patentes em que a nacionalidade de todos os inventores é igual à da matriz. Para caracterizar as competências da empresa são utilizadas todas as patentes, as nacionais e internacionais, e tanto as que representam cooperações como as que não representam. 
as capacitações tecnológicas do país de origem e o país de destino, a aquisição de tecnologia estrangeira pode tomar um caráter estratégico para a corporação (por exemplo: as vantagens locacionais dos Estados Unidos em biotecnologia).

QUADRO 1

Estratégias corporativas de internacionalização tecnológica

\begin{tabular}{c|l|l}
\hline \multirow{2}{*}{$\begin{array}{c}\text { Atividade tecnológica } \\
\text { corporativa no país de origem }\end{array}$} & \multicolumn{2}{c}{$\begin{array}{c}\text { Atividade tecnológica corporativa } \\
\text { no país hospedeiro }\end{array}$} \\
\cline { 2 - 3 } & \multicolumn{1}{c}{ Forte } & \multicolumn{1}{c}{ Fraca } \\
\hline \multirow{2}{*}{ Fraca } & I. Technology-seeking & IV. Market-seeking \\
& VTR Doméstica $<1$ & VTR Doméstica $<1$ \\
& VTR Hospedeiro $>1$ & VTR Hospedeiro $<1$ \\
\hline \multirow{2}{*}{ Forte } & III. Home-base- & II. Home-base- \\
& augmenting & exploiting \\
& VTR Doméstica $>1$ & VTR Doméstica $>1$ \\
& VTR Hospedeiro $>1$ & VTR Hospedeiro $<1$ \\
\hline
\end{tabular}

Fonte: Patel e Vega (1999); Le Bas e Sierra (2002).

A estratégia tipo II, denominada home-base-exploiting, consiste na exploração de uma tecnologia em que a corporação detém vantagem competitiva adquirida no seu país de origem em regiôes onde há debilidade tecnológica nessa mesma tecnologia. A P\&D transacional tem como finalidade prover de suporte técnico as subsidiárias localizadas nessas mesmas regiōes e adaptar os processos ou os produtos às condiçôes do país de destino. Ou seja, trata-se de um tipo de P\&D "orientado à eficiência". É o tipo de estratégia motivada pelo lado da demanda no sentido de dar lugar a P\&D adaptativa e aprendizado focalizado. As empresas apenas tratam de explorar seu conhecimento base e seu capital tecnológico no curto prazo e não necessariamente haverá esforços de melhora tecnológica substantivos.

A estratégia tipo III é a home-base-augmenting FDI in $R \& D$, que tem como objetivo desenvolver tecnologias em que há uma forte vantagem doméstica e no país de destino. O objetivo é monitorar ou adquirir vantagens tecnológicas em campos técnicos complementares aos que a empresa possui, ou bem capturar as externalidades geradas por instituições ou firmas locais. Este tipo de estratégia é orientado pela oferta, dado que a corporação trata de aproveitar as economias de aglomeração que existem em torno do desenvolvimento de uma tecnologia avançada num determinado lugar. Com esta estratégia, a corporação adquire capacidade de absorção e fortalecimento de seu core de competências tecnológicas. 
A estratégia tipo IV é chamada de market-seeking FDI in $R \& D$ e se revela em campos técnicos nos quais a empresa não tem vantagem doméstica e onde o país tampouco revela vantagem. Os autores indicam que se trata do resultado de atividades de fusões e aquisições, provavelmente de tipo horizontal, que não foram motivadas para a o fortalecimento das competências tecnológicas centrais e carentes de componente estratégico.

Considerando a hipótese de que cooperação tecnológica transnacional é uma estrutura que permite governar as ações de internacionalização da $\mathrm{P} \& \mathrm{D}$, cabe supor que os motivos para a internacionalização da cooperação em P\&D são similares aos da internacionalização da P\&D. Neste sentido, os indicadores de Patel e Vega (1999) e Le Bas e Sierra (2002) podem ser adaptados para a identificação das principais estratégias nacionais de cooperação internacional. A importância de cada estratégia vem representada a partir do peso que significa o número de cooperaçôes internacionais relativas aos setores que cumprem as condiçóes do Quadro 2 relativas à VTR $^{8}$ dos países envolvidos na cooperação.

Quando a cooperação acontece num setor em que algum dos parceiros está especializado, mas o outro parceiro não está, entende-se que o motivo da cooperação é a captura de competências tecnológicas. Na estratégia tipo 1, o país de origem trata de compensar fraquezas internas em setores em que o país parceiro tem comprovada vantagem tecnológica, valendo-se, para isso, da cooperação internacional. Trata-se da exploração das vantagens tecnológicas do parceiro em tecnologias nas quais o país não está especializado, ou seja, se corresponde com estratégias de internacionalização do tipo technology seeking ou host-country-exploiting.

$\mathrm{Na}$ estratégia tipo 2, desde o ponto de vista do país que detém a vantagem, a $\mathrm{P} \& \mathrm{D}$ transacional pode ter como finalidade a provisão de suporte técnico às subsidiárias localizadas no exterior para adaptar os processos ou os produtos às condiçôes do país de destino. Esta estratégia de cooperação se corresponde com estratégias de internacionalização home-base-exploiting. Neste caso, pode haver desenvolvimento de redes externas em que o transbordamento do conhecimento ocorre de centros de excelência para o setor privado em troca de investimento e suporte financeiro. Outras motivações podem estar associadas ao compartilhamento de riscos, incertezas ou

8 A vantagem tecnológica revelada (VTR) se calcula como ${ }^{V T R}=\frac{p_{t}^{i}}{p_{i}^{p R o}}$; onde $p_{i}^{j}$ representa o peso do setor i no país j e onde $p_{i}^{E P O}$ refere-se ao peso do setor industrial i no total EPO. Quando a $V T R \geq 1,0$ o país se encontra especializado nas tecnologias relativas ao setor i e, se menor que 1, não especializado. A VTR representa a importância relativa de cada tecnologia em cada país. 
restriçôes financeiras. Considerando que os motivos para a cooperação são de caráter tecnológico, as estratégias 1 e 2 respondem pela captura de competências técnicas.

QUADRO 2

Estratégias nacionais de cooperação internacional

\begin{tabular}{|c|c|c|c|c|c|}
\hline Classificação & $\begin{array}{c}\text { VTR } \\
\text { nacional } \\
\text { do país }\end{array}$ & $\begin{array}{c}\text { VTR } \\
\text { nacional } \\
\text { do } \\
\text { parceiro }\end{array}$ & $\begin{array}{l}\text { Coeficiente } \\
\text { de especia- } \\
\text { lização } \\
\text { técnica em } \\
\text { cooperação } \\
\text { internacional }\end{array}$ & $\begin{array}{l}\text { Coeficiente de } \\
\text { especialização } \\
\text { em coope- } \\
\text { ração total }\end{array}$ & $\begin{array}{l}\text { Estra- } \\
\text { tégias }\end{array}$ \\
\hline $\begin{array}{l}\text { Captura de compe- } \\
\text { tências do parceiro }\end{array}$ & $<1$ & $>1$ & $>1$ & - & E1 \\
\hline $\begin{array}{l}\text { Captura de competên- } \\
\text { cias do próprio país }\end{array}$ & $>1$ & $<1$ & - & - & E2 \\
\hline Complementaridade & $>1$ & $>1$ & $>1$ & - & E3 \\
\hline Imperativo setorial & $<1$ & $<1$ & - & $>1$ & E4 \\
\hline $\begin{array}{l}\text { Desenvolvimento } \\
\text { circunstancial }\end{array}$ & $<1$ & $<1$ & - & $<1$ & E5 \\
\hline
\end{tabular}

1- Coeficiente da especialização da cooperação internacional

2- VTR da cooperação total

Fonte. Elaboração das autoras.

Quando a cooperação se localiza em tecnologias em que os países envolvidos estão especializados, o motivo para a cooperação pode estar vinculado à busca pela complementaridade do conhecimento, o que significaria duplicação ou reprodução de esforços tecnológicos. Esta estratégia contabiliza o número de cooperações para cada setor em que o valor da VTR é superior a 1 tanto para os países parceiros quanto para o próprio país e onde ainda o país especializa internacionalmente sua atividade de cooperação. ${ }^{9}$ A estratégia tipo 3 de cooperação se corresponde com uma estratégia home-base-aumenting de internacionalização, ou seja, com a busca de ativos tecnológicos complementares, desenvolvimento de conhecimento de fronteira ou com a exploração de nichos tecnológicos. Esta estratégia pode ser o caso de EMN cooperando

9 Medido por meio do coeficiente de especialização técnica em cooperação internacional (ISCi) medido Como $I S C_{i}=\frac{c_{i, J}^{I J}}{c^{\prime}}$, onde $c_{i}^{I, J}$ é o peso que representam as cooperações internacionais do setor industrial $i$ no país $J$ sobre o total de cooperações internacionais do país $J$ e, $c_{i}^{J}$ corresponde ao peso das cooperações totais do setor $i$ e do país $J$ no total de cooperação tecnológica do país $J$. Se ISC i>1,0 isso significa que o país especializa sua cooperação internacionalmente. 
com empresas fornecedoras altamente especializadas em tecnologias relacionadas (que pertencem ao mesmo setor para um nível de agregação de dois dígitos).

Finalmente, uma parte das cooperações acontece em tecnologias nas quais nenhum dos países parceiros registra especialização (VTR menor que 1). Dado que neste caso a busca pela exploração de vantagens é impossível, duas hipóteses foram contempladas. A primeira é que existe um imperativo setorial que empurra à cooperação independentemente da existência de vantagens nacionais. Este efeito se mede por meio do coeficiente de especialização em cooperação, $C E C_{i}=\left(c_{i, j} / c_{j}\right) /$

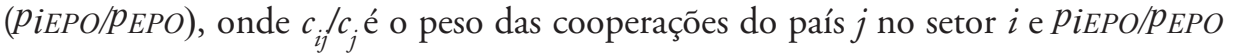
corresponde ao peso que representam as patentes do setor $i$ no total de patentes da base da EPO. Se $C E C_{i}$ for maior que um, a causa da cooperação pode estar associada a um imperativo setorial (estratégia 4), ou seja, a cooperação é relevante para o setor independentemente se representa vantagem tecnológica para algum dos parceiros. Se não, o motivo da cooperação responde a desenvolvimento circunstancial (estratégia 5), ou seja, tem caráter esporádico, associado a joint-ventures econômicas ou parcerias que surgiram respondendo a eventos específicos, como editais públicos para desenvolvimento de projetos tecnológicos.

Os Estados Unidos concentram-se nas estratégias 2 e 3, agregando 75,7\% das cooperaçôes com seus principais parceiros (Tabela 4). A estratégia do tipo 2 é a de maior percentagem $(49,8 \%)$, concentrando-se nos setores de tabaco, farmacêutico, pesticidas, instrumentos e aparelhos de medida e material médico-cirúrgico e ortopédico. A estratégia tipo 3 é especialmente relevante no setor de papel.

A estratégia do tipo 1 , de menor relevância em relação às anteriores $(11,8 \%)$, é relativamente importante em automóveis, reboques e semirreboques. A estratégia do tipo 5 (desenvolvimento conjunto circunstancial) absorve $11,3 \%$, sendo dominante nos setores de máquinas de uso geral, maquinas e tratores, aparelhos de uso doméstico, materiais de distribuição e controle elétricos, outros equipamentos elétricos, outro material de transporte e móveis e outras indústrias transformadoras. Estes casos devem responder a acordos de cooperação internacionais promovidos e financiados por governo, ou ainda parcerias do tipo público-privado em que os riscos e custos são compartilhados. Finalmente, a motivação relacionada com imperativos setoriais é marginal, representando $1,2 \%$ do total de cooperações internacionais, com predominância apenas no setor de alimentos e bebidas.

O padrão das estratégias do Japão é diferente ao seguido pelos Estados Unidos (Tabela 4). A principal estratégia do Japão foi a do tipo 3 (complementaridade de conhecimento), com $38,1 \%$ dos casos e concentrada nos setores de petróleo, aparelhos de uso doméstico e outros equipamentos elétricos. 
Ana Urraca Ruiz, Cynthia Bastos Gomes

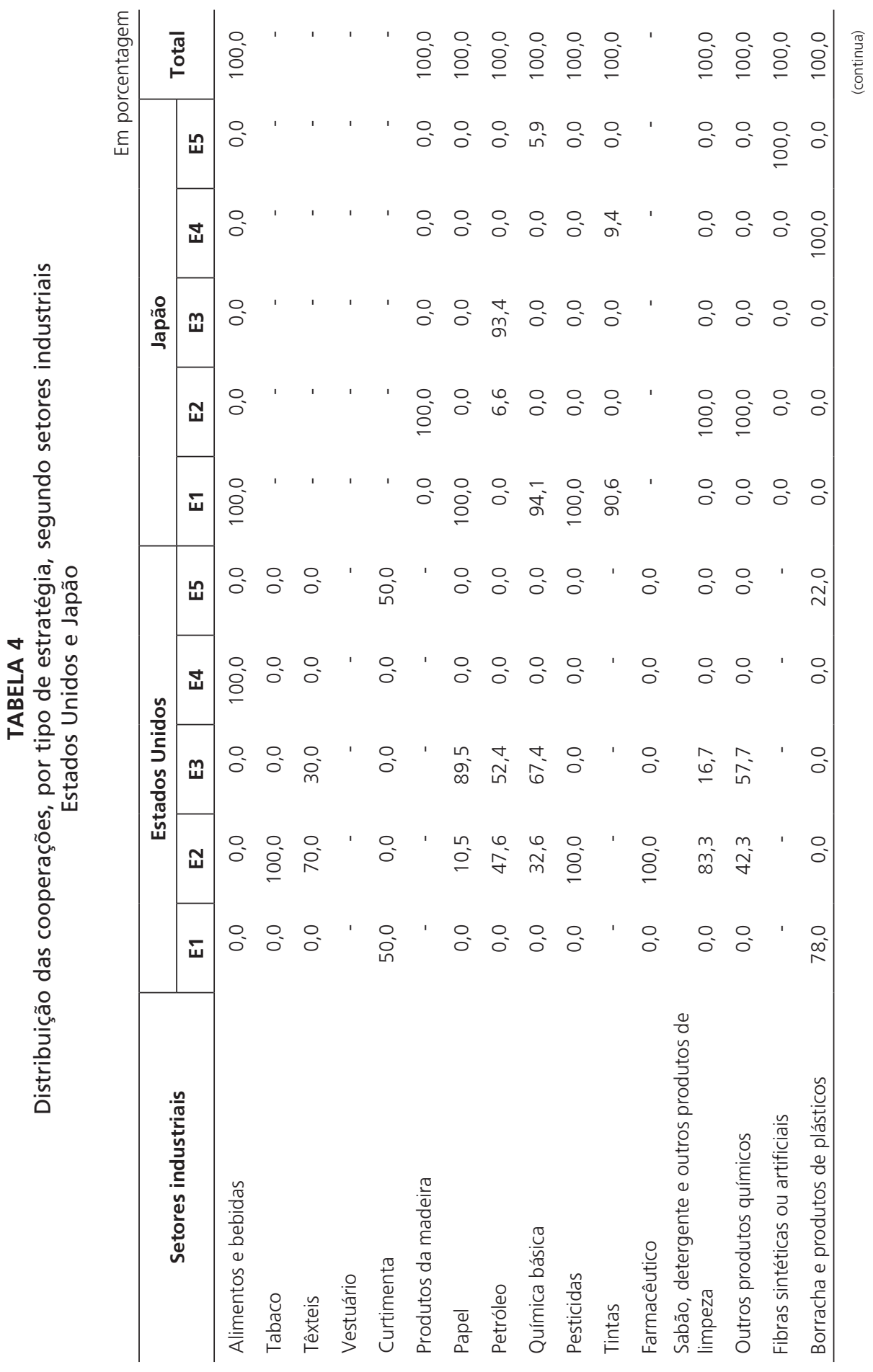

372 Revista Brasileira de Inovação, Campinas (SP), 12 (2), p. 345-384, julho/dezembro 2013 
Estratégias de cooperação tecnológica transnacional em Estados Unidos e Japão

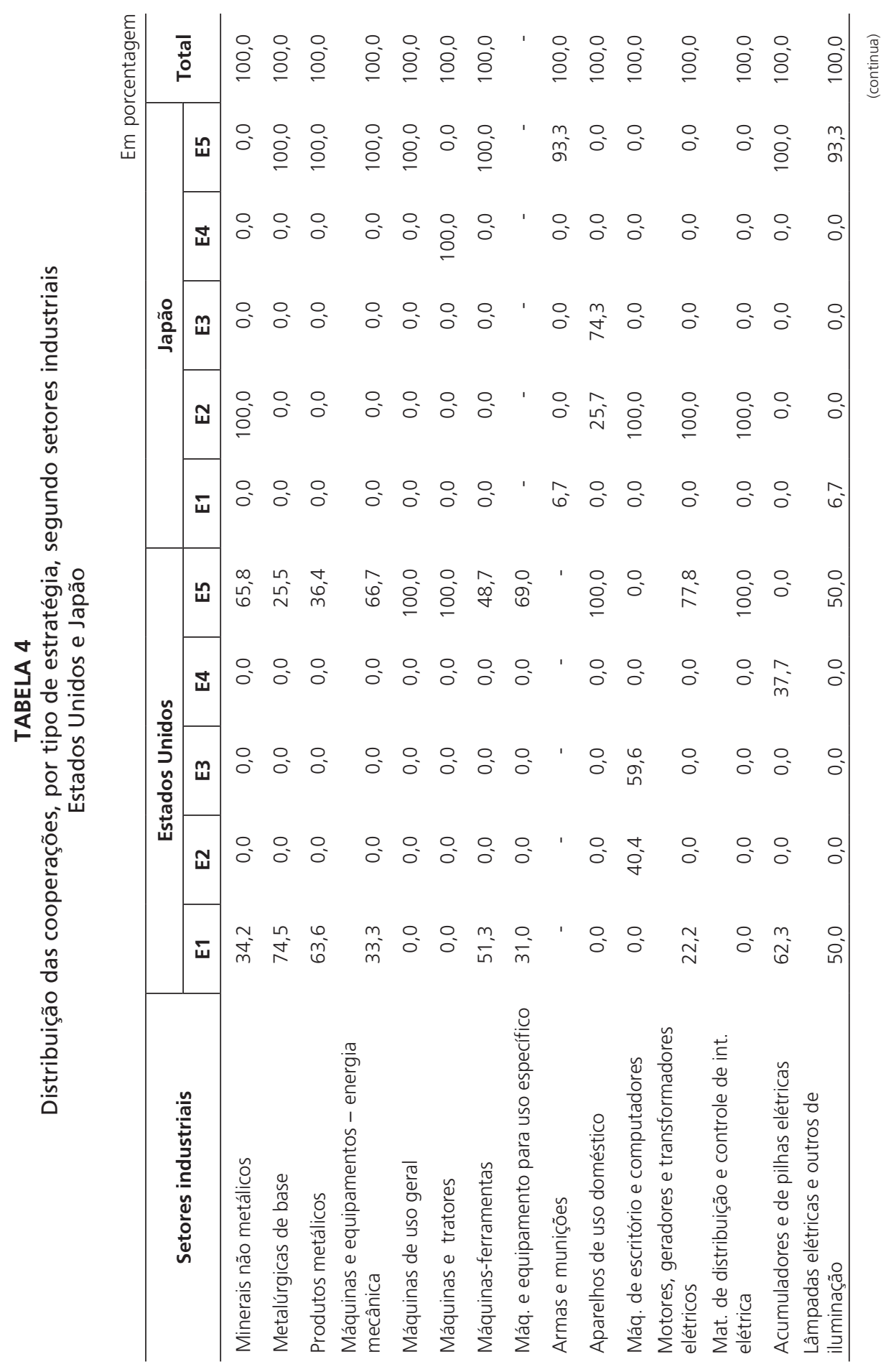




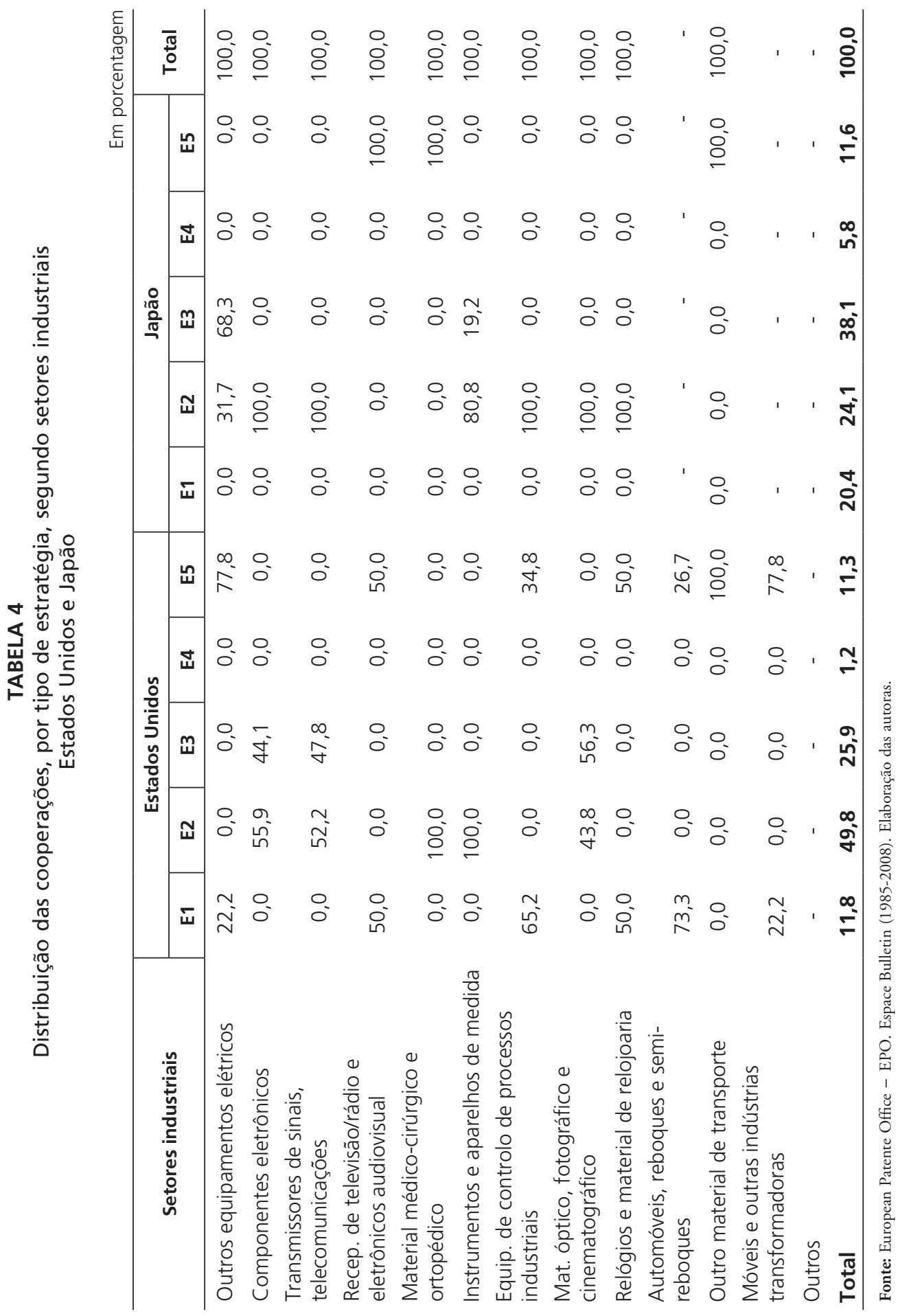


A segunda estratégia mais importante é a do tipo 2, ou seja, aproveitamento externo de suas competências ou exploração de mercados externos. Esta estratégia ocupou $20,7 \%$ dos casos de cooperação internacional e se concentrou $100 \%$ num grande número de setores: produtos de madeira; sabão, detergente e produtos de limpeza; outros produtos químicos; minerais não metálicos; máquinas de escritório e computadores; motores, geradores e transformadores elétricos; materiais de distribuição e controle elétricos; componentes eletrônicos; transmissores de sinais e telecomunicaçóes; equipamento de controlo de processos industriais; material óptico, fotográfico e cinematográfico; e relógios e material de relojoaria.

Com um peso muito similar se encontra a estratégia tipo 1 , que caracteriza a extensão e exploração de competências domésticas, absorvendo 20,4\% das cooperações internacionais. Este tipo de estratégia se localizou fortemente nos setores de papel, química básica, pesticidas e tintas.

A estratégia do tipo 5 (desenvolvimento conjunto circunstancial) ocupa 11,6\% das cooperações japonesas, sendo predominante nos setores de fibras sintéticas ou artificiais, metalurgia de base, produtos metálicos, máquinas e equipamentos, máquinas de uso geral, máquinas ferramentas, armas e munições, acumuladores e pilhas elétricas, lâmpadas elétricas e outros artefatos de iluminação, recepções de TV, rádio e eletrônica audiovisual, material médico-cirúrgico e outro material de transporte. Tendo vista que ocupam quase todos os setores mecânico e parte do eletroeletrônico, estas estratégias devem responder a acordos de cooperação internacional promovidos pelo governo japonês. Finalmente, a estratégia tipo 4 ocupou $5,1 \%$ nas cooperações internacionais e foi predominante nos setores de borracha e plásticos e máquinas e tratores.

A estratégia tipo 3, relativa à complementaridade tecnológica, é mais importante nas parcerias com Japão, Suíça e Holanda, embora com pesos moderados. Já a estratégia tipo 5 referente a eventos circunstanciais revela-se como a mais importante nas cooperações com Grã Bretanha (43,6\%), embora com um peso similar ao que representa a estratégia tipo $2(41,7 \%)$.

As Tabelas 5 e 6 apresentam a distribuição das cooperações entre as diversas estratégias e de acordo com os principais parceiros, para os Estados Unidos e Japão. Os resultados para os Estados Unidos mostram que a exploração das competências tecnológicas dos países parceiros não foi dominante em nenhum dos países mais representativos de sua rede de cooperação internacional. Já a estratégia tipo 2 foi fortemente dominante nas parcerias com Áustria (100\%), Itália (83,8\%), Alemanha $(71,6 \%)$ e, em menor medida, com Canadá $(38,8 \%)$, França $(67,7 \%)$, Holanda 
(45,8\%), Dinamarca (56,0\%), Bélgica $(43,8 \%)$ e Austrália (56,3\%). Ou seja, as parcerias vinculadas ao estabelecimento de redes externas nos Estados Unidos ou no país de destino na busca de exploração de particularidades de mercado é a principal estratégia que se revela para a maior parte dos principais parceiros da rede americana de cooperação internacional.

Os resultados para o Japão mostram um padrão de cooperação tecnológica diferente. A busca pela complementaridade tecnológica (estratégia tipo 3) caracteriza as cooperações com Estados Unidos (40,5\%), Alemanha (42,6\%), Holanda (54,5\%) e, principalmente, Coria do Sul (76,9\%). Já a estratégia tipo 2, associada ao estabelecimento de redes externas no Japão ou à exploração de mercados exteriores, é mais relevante na Grã Bretanha (61,8\%), Canadá (41,7\%) e Áustria $(62,5)$ e, com certa importância, também na Alemanha (40,4\%) e Dinamarca (41,7\%). Finalmente, a exploração de vantagens domésticas (estratégia tipo 1) apresenta-se relevante nas parcerias com Suíça $(47,6 \%)$ e Dinamarca $(50,5 \%)$.

TABELA 5

Distribuição das cooperações de Estados Unidos, por tipo de estratégia, segundo países parceiros

\begin{tabular}{l|c|c|c|c|c|c|c}
\hline \multicolumn{1}{c|}{ Parceiros } & E1 & E2 & E3 & E4 & E5 & Total & $\begin{array}{c}\text { Peso } \\
\text { (1) }\end{array}$ \\
\hline Japão & 10,4 & 30,9 & 46,4 & 0,5 & 11,7 & 100,0 & 38,7 \\
Alemanha & 16,0 & 71,6 & 10,3 & 1,4 & 0,7 & 100,0 & 25,5 \\
Grã Bretanha & 7,6 & 41,7 & 4,3 & 2,8 & 43,6 & 100,0 & 7,5 \\
Canadá & 8,6 & 38,8 & 23,7 & 0,0 & 28,9 & 100,0 & 5,4 \\
França & 21,1 & 67,7 & 1,2 & 3,1 & 6,8 & 100,0 & 5,7 \\
Suíça & 26,1 & 28,3 & 37,0 & 2,2 & 6,5 & 100,0 & 1,6 \\
Holanda & 1,3 & 45,8 & 42,6 & 0,0 & 10,3 & 100,0 & 5,5 \\
Dinamarca & 24,0 & 56,0 & 8,0 & 0,0 & 12,0 & 100,0 & 0,9 \\
Itália & 9,9 & 83,8 & 0,0 & 3,6 & 2,7 & 100,0 & 3,9 \\
Bélgica & 8,3 & 43,8 & 31,3 & 0,0 & 16,7 & 100,0 & 1,7 \\
Austrália & 18,8 & 56,3 & 6,3 & 6,3 & 12,5 & 100,0 & 1,1 \\
Áustria & 0,0 & 100,0 & 0,0 & 0,0 & 0,0 & 100,0 & $\mathbf{2 , 3}$ \\
Total & $\mathbf{1 1 , 8}$ & $\mathbf{4 9 , 8}$ & $\mathbf{2 5 , 9}$ & $\mathbf{1 , 2}$ & $\mathbf{1 1 , 3}$ & $\mathbf{1 0 0 , 0}$ & $\mathbf{5 6 , 6}$ \\
\hline
\end{tabular}

Fonte: European Patente Office - EPO. Espace Bulletin (1978-2008). Elaboração das autoras.

(1) No total de cooperaçóes internacionais americanas. 
TABELA 6

Distribuição das cooperações de Japão, por tipo de estratégia, segundo países parceiros

\begin{tabular}{l|c|c|c|c|c|c|c}
\multicolumn{1}{c|}{ Parceiros } & E1 & E2 & E3 & E4 & E5 & Total & $\begin{array}{c}\text { Peso } \\
\mathbf{( 1 )}\end{array}$ \\
\hline Estados Unidos & 24,7 & 16,5 & 40,5 & 4,2 & 14,1 & 100,0 & 60,9 \\
Alemanha & 2,2 & 40,4 & 42,6 & 9,3 & 5,5 & 100,0 & 12,4 \\
Holanda & 3,8 & 15,2 & 54,5 & 12,9 & 13,6 & 100,0 & 9,0 \\
Grã Bretanha & 26,8 & 61,8 & 0,0 & 5,7 & 5,7 & 100,0 & 8,4 \\
Suíça & 47,6 & 19,0 & 33,3 & 0,0 & 0,0 & 100,0 & 2,9 \\
Canadá & 30,6 & 41,7 & 8,3 & 2,8 & 16,7 & 100,0 & 2,4 \\
Dinamarca & 50,0 & 41,7 & 0,0 & 8,3 & 0,0 & 100,0 & 0,8 \\
Coreia do Sul & 0,0 & 10,3 & 76,9 & 10,3 & 2,6 & 100,0 & 2,7 \\
Áustria & 0,0 & 62,5 & 0,0 & 12,5 & 25,0 & 100,0 & 0,5 \\
Total & $\mathbf{2 0 , 4}$ & $\mathbf{2 4 , 1}$ & $\mathbf{3 8 , 1}$ & $\mathbf{5 , 8}$ & $\mathbf{1 1 , 6}$ & $\mathbf{1 0 0 , 0}$ & $\mathbf{5 8 , 5}$ \\
\hline
\end{tabular}

Fonte: European Patente Office - EPO. Espace Bulletin (1978-2008). Elaboração das autoras.

(1) No total de cooperaçóes internacionais japonesas.

\section{Discussão e conclusões}

O objetivo deste trabalho foi desenvolver uma metodologia que permitisse identificar as principais estratégias de cooperação tecnológica transnacional de acordo com as motivações que levam à internacionalização e à cooperação tecnológica fora das fronteiras nacionais. $\mathrm{O}$ estudo propôs desenvolver uma metodologia a partir do uso de patentes, adaptando os indicadores de internacionalização de P\&D elaborados por Patel e Vega (1999) e Le Bas e Sierra (2002) para a internacionalização da cooperação. Posteriormente, aplicou-se esta metodologia aos casos de Estados Unidos e Japão para identificar possíveis diferenças de comportamento entre líderes tecnológicos. As patentes se configuram como uma fonte de informação adequada a este tipo de análise porque oferecem informações sobre competências tecnológicas da empresa e porque, quando depositadas em conjunto por agentes sem vínculos de propriedade, indicam a existência de esforços conjuntos em pesquisa, ou seja, cooperação.

A metodologia desenvolvida identifica cinco tipos de estratégias. As duas primeiras referem-se à captura de competências tecnológicas por parte de algum dos parceiros sobre o outro. A terceira reflete a exploração de capacitações mútuas na busca pela exploração de nichos tecnológicos ou pelo avanço na fronteira do 
conhecimento. A quarta e a quinta fogem da ideia de captura de competências. A quarta refere-se a estratégias de cooperação definidas por imperativos setoriais específicas no país de origem. A quinta revela os casos de cooperação vinculada à exploração de mercados locais ou para atender a eventos determinados (por exemplo, os casos de joint-ventures tecnológicas ou acordos de cooperação com objetivo de aceder a financiamento).

Os resultados por países mostram que o padrão de cooperação do Japão é a complementaridade tecnológica associada à duplicação de esforços, isto é, a exploração de vantagens conjuntamente com seus parceiros. A captura bidirecional de competências é também relevante. A exploração de vantagens internas acontece fundamentalmente nos setores mecânicos, eletrônicos e instrumentos. Suas principais parcerias ocorrem dentro da tríade, concretamente em países que se situam, para cada tecnologia, na fronteira tecnológica e que têm elevada dimensão econômica, particularmente, nos Estados Unidos (SHIMIZUTANI; TODO, 2008). No entanto, o Japão desenvolve também parcerias com países que adquirem certa centralidade na rede e que não pertencem à tríade, como Coreia do Sul e Canadá.

O padrão da cooperação tecnológica transnacional para os Estados Unidos assemelha-se ao do Japão com relação aos principais países parceiros e à importância deles na cooperação internacional. No caso americano, os países que adquirem maior centralidade na sua rede de cooperação internacional também encontram-se na tríade Estados Unidos-Japão-Europa. A cooperação internacional de P\&D caracteriza-se, principalmente, pela exploração de competências próprias com parceiros não especializados, o que significa a existência de redes externas nos Estados Unidos por parte de corporações transnacionais estrangeiras ou o desenvolvimento de P\&D focalizado de tipo adaptativo, realizado por subsidiárias americanas no exterior.

Estes resultados são consistentes com os encontrados por Patel e Vega (1999) e Le Bas e Sierra (1999), em que as estratégias de internacionalização dominantes são as denominadas "home base aumenting" e "home base exploting". A estratégia home-base-aumenting relaciona-se com a estratégia tipo 3 de cooperação transacional, dado que em ambas existe o desenvolvimento de tecnologias em que há uma forte vantagem doméstica e no país de destino. A estratégia "home base exploting" relaciona-se com a estratégia tipo 2, ou seja, à exploração de vantagens tecnológicas locais com parceiros que carecem de tal vantagem.

A estratégia tipo 1 definida para cooperação tem alguma importância e, de certa forma, se corresponde com a estratégia a "technology-seeking FDI in $R \& D$ ” ou "host-country-exploiting". 
Em resumo, a consistência entre estratégias permite concluir que as estratégias de cooperação transacional, quando analisadas no nível nacional, respondem em grande medida às estratégias de internacionalização realizadas pelas GCT. À medida que esta forma de internacionalização da P\&D permite o desenvolvimento de redes externas, seus efeitos nos países parceiros, assim como possíveis mudanças de estratégia em certos setores após a assinatura do acordo TRIPs, deverão ser objeto de futuros trabalhos.

\section{Referências bibliográficas}

ALVES, J. D. O.; DEL-VECCHIO, R.; INHUDES, A. Transparência econômica do Banco Central do Brasil: uma análise matemática das surpresas. In: XL SIMPÓSIO BRASILEIRO DE PESQUISA OPERACIONAL. Anais... João Pessoa, 2008.

ANDRADE, E.; SAMPAIO, R.; SILVA, G. Notas em Matemática Aplicada. SBMAC, 2007. ARCHIBUGI, D.; IAMMARINO, S. The policy implications of the globalisation of innovation. Research Policy, n. 28, p. 317-336, 1999.

ARCHIBUGI, D.; MICHIE, J. The globalisation of technology: a new taxonomy. Cambridge Journal of Economics, n. 19, p. 121-140, 1995.

ARORA, A.; GAMBARDELLA, A. The changing technology of technological change. General and abstract knowledge and the division of innovative labour. Research Policy, $\mathrm{n}$. 23, p. 523-32, 1994.

BLANC, H.; SIERRA, C. The internalisation of R\&D by multinationals: a trade-off between external and internal proximity. Cambridge Journal of Economics, n. 23, p. 187-206, 1999.

BEERS, C.; BERGHALL, E;.POOT, A. P. R\&D Internationalization, R\&D Collaboration and Public Knowledge Institutions in Small Economies: evidence from Finland and the Netherlands". Research Policy, v. 37, n. 2, p. 294-308, 2008.

BONACICH, P. Eigenvector-like measures of centrality for asymmetric relations, Social Networks, n. 23, p. 191-201, 2001.

CANTWELL, J. The internationalization of technological activity and its implications for competitiveness. In: GRANSTRAND, O.; HAKANSON, L.; SJOLANDER, S. (Eds.). Technology management in international business.. New York:Wiley, 1992, p. 75-95.

The gobalisation of technology: what remains of the product cycle model. Cambridge Journal of Economics, n. 19, p. 155-74, 1995. 
Ana Urraca Ruiz, Cynthia Bastos Gomes

CANTWELL, J.; IAMMARINO, S. MNCs, technological innovation and regional syste$\mathrm{ms}$ in the EU: some evidence in the Italian case. International Journal of the Economics of Business, v. 5, n. 3, p. 383-408, 1998.

CANTWELL, J.; JANNE, O. The role of multinational corporations and national states in the globalization of innovatory capacity: the european perspective. Technology Analysis \& Strategic Management, v. 12, n. 2, 2000.

CASSIOLATO, J. E.; LASTRES, H.; SZAPIRO, M.; VARGAS, M. A. Local systems of innovation in Brazil, development and transnational corporation: a preliminary assessment based on empirical results of a research project. 2001 (DRUID conference paper).

COHEN,W. M.; LEVINTHAL, D. A. Innovation and learning: the two faces of R\&D. The Economic Journal, n. 99, p. 569-596, 1989.

DEL-VECCHIO, R.; GALVÃO, D.; LOURES, R.; LIMA, L. Medidas de centralidade da Teoria dos Grafos aplicada a fundos de açôes no Brasil. In: XLI SIMPÓSIO BRASILEIRO DE PESQUISA OPERACIONAL. Anais... Porto Seguro. 2009.

DUNNING, J. H. Explaining changing patterns of international production: in defense of eclectic theory. Oxford Bulleting of Economics and Statistics, n. 41, p. 269-295, 1979.

. Multinational enterprises and the globalization of innovatory capacity. Research Policy, n. 23, p. 67-89, 1994.

ERBER, F. S.; CASSIOLATO, J. E. Resumo de política industrial: teoria e prática no Brasil e na OECD. Revista de Economia Politica, v. 17, n.2 (66), p. 32-60, 1997.

FEOFILOFF, P. Exercício de Teoria dos Grafos. 2006. Disponível em: <http://www.ime.usp. br/ $\sim$ pf/>. Acesso em: 15 dez. 2009.

FILIPPAIOS, F.; PAPANASTASSIOU, M.; PEARCE, R.; RAMA, R., New forms of organisation and R\&D internationalisation among the world's 100 largest food and beverages multinationals. Research Policy n. 38, p. 1032-1043, 2009.

FLORIDA, R., The globalisation of R\&D: results of a survey of foreign-affiliated R\&D laboratories in the USA. Research Policy, v. 26, n. 1, p. 85-103, 1997.

GERYBADZE A.; REGER, G. Globalisation of R\&D: recent changes in the measurement of innovation in transnational corporations. Research Policy, n. 28, p. 251-274, 1999.

GHOSHAL, S.; BARTLETT, C. A. The multinational corporation as an inter-organisational network. Academy of Management Review, v. 15, n. 4, p. 603-25, 1990.

Building the entrepreneurial corporation: new organizational processes, new managerial tasks. European Management Journal, v. 13, n. 2, p. 139-55, 1995. 
GRANSTRAND, O. The economics and management of intellectual property. Cheltenham, U.K.: Edward Elgar Publishing Ltd, 1990.

GRANSTRAND, O.; HAKANSON, I.; SJOLANDER, S. Internationalization of R\&D - a survey of some recent research. Research Policy, v. 22, p. 413-30, 1993.

HAGEDOORN, J. Global strategies in innovation: networks in research and production. IJTM, Special Publication on the Role of Technology in Corporate Policy. 1991.

HAGEDOORN, J.; SOETE, L. The internationalisation of science and technology policy: how do 'national' systems cope? Science and technology policy research. Tokyo: Mita Press, National Institute for Science and Technology Policy,1991.

HIRATUKA, C. Internacionalização de atividades de pesquisa e desenvolvimento das empresas transnacionais: análise da inserção das filiais brasileiras. São Paulo em Perspectiva, v. 19, n. 1, p. 105-114, 2005.

ITO, B.; WAKASUGI, R. What factors determine the mode of overseas R\&D by multinationals? Empirical evidence. Research Policy, n. 36, p. 1275-1287, 2007.

IWASA, T.; ODAGIRI, H. Overseas R\&D, knowledge sourcing and patenting: an empirical study of Japanese R\&D investment in the US. Research Policy, n. 33, p. 807-828, 2004.

KUEMMERLE, W. Foreign direct investment in industrial research in the pharmaceutical and electronics industries - results from a survey of multinational firms. Research Policy, n. 28, p. 179-193, 1999.

KUMAR, N. Determinants of location of overseas R\&D activity of multinational enterprises: the case of US and Japanese corporations. Research Policy, n. 30, p. 159-174, 2001.

LALL, S. Export performance technological upgrading and foreign direct investment strategies in the Asian newly industrializing economies with special reference to Singapore. Desarollo Productivo, n. 88, 2000.

Investment and Technology policies for competitiveness: review of successful country experiences. New York and Geneva: , United Nations, 2003.

LE BAS, C.; SIERRA, C. Location versus home country advantages 'in R\&D activities: some further results on multinationals' locational strategies. Research Policy, n. 31, p. 589-609, 2002.

LEVIN, R. C.; KLEVORICK, A. K.; NELSON, R. R.; WINTER S. G. Appropiating the returns from industrial research and development. Brookings Papers on Economic Activity, n. 3, p. 783-820, 1987.

LÖÖF, H. Multinational enterprises and innovation: firm level evidence on spillover via R\&D collaboration. Journal of Evolutionary Economics, n. 19, p. 41-71, 2009. 
Ana Urraca Ruiz, Cynthia Bastos Gomes

MA, Z.; LEE, Y. Patent application and technological collaboration in inventive activities: 1980-2005. Technovation, n. 28, p. 379-390, 2008.

MEYER-KRAMER, F.; REGUER, G. New perspectives on the innovation strategies of multinational enterprises: lessons for technology policy in Europe. Research Policy, n. 28, p. 751-776, 1999.

ODAGIRI, H.; YASUDA, H. The determinants of overseas R\&D by Japanese firms: an empirical study at the industry and company levels. Research Policy, v. 25, n. 7, p. 10591079, 1996.

OST - Observatoire des Sciences et des Techniques. Science and technologie: indicateurs. Paris : Economica, 1998.

PAPANASTASSIOU, M.; PEARCE, R. Decentralisation of technology and organisational restructuring in the multinational enterprise group. In: EUROPEAN INTERNATIONAL BUSINESS ACADEMY, 21st ANNUAL CONFERENCE. Urbino, December 1995.

PATEL, P.; VEGA, M. Patterns of internationalisation of corporate technology: location vs. home country advantages. Research Policy, n. 28. P. 145-155, 1999.

PATEL, P.; PAVITT, K. The technological competences in the world's largest firms: complex and path dependent, but not much variety. Research Policy, n. 26, p. 141-156, 1997.

PEARCE, R. World product mandates and multinational enterprise specialization. Scandinavian International Business Review, n. 2, p. 38-58, 1992.

ROCHA, C. Competências tecnológicas e cooperação interfirma. Resultados da análise de patentes depositadas em conjunto. Tese (Doutorado). Rio de Janeiro: IE/UFRJ, 1995.

RUGMAN, A. Inside the multinationals: the economics of internal markets. Londres: Ed. Croom Helm, 1981.

SERAPIO, M.; DALTON, D. Foreign R\&D facilities in the United States. Research Technology Management, v. 36, n. 6, p. 33-39, 1993.

SCHMOCH et al. Linking technology areas to industrial sectors. Final Report to the European Commission, DG Research. Paris, Brighton: Karlsruhe, 2003.

SHIMIZUTANI, S.; TODO, Y. What determines overseas R\&D activities? The case of Japanese multinational firms. Research Policy, n. 37, p. 530-544, 2008.

UNCTAD. World investment report: TNCs and export competitiviness. Nova York: Nações Unidas, 2002.

VERNON, R. International investment and international trade in the product cycle. Quarterly Journal of Economics, n. 80, p. 190-207, 1966. 
Estratégias de cooperação tecnológica transnacional em Estados Unidos e Japão

VON ZEDTWITZ, M.; GASSMANNB, O. Market versus technology drive in R\&D internationalization: four different patterns of managing research and development. Research Policy, n. 31, p. 569-588, 2002.

ZANFEI, A. Transnational firms and the changing organisation of innovative activities. Cambridge Journal of Economics, n. 24, p. 515-542, 2000.

ENDEREÇOS PARA CORRESPONDENCIA

Ana Urraca Ruiz - anaurracaruiz@gmail.com Rua Tonelero, 4, apto. 103, Copacabana 22030-002 - Rio de Janeiro (RJ)

Cynthia Bastos Gomes - gb.cynthia@gmail.com Rua Lopes Trovão, 294, apto. 1503, Bloco 1, Icaraí 24220-071 - Niterói (RJ) 